UNIVERSIDADE DE SÃO PAULO

ESCOLA DE ENGENHARIA DE SÃO CARLOS

\title{
SISTEMA MECATRÔNICO PARA REABILITAÇÃO PÓS FRATURA DA EXTREMIDADE DISTAL DO RÁDIO
}

Gisele Gonsalez Ito

Dissertação apresentada à Escola de Engenharia de São Carlos da Universidade de São Paulo, para o Título de Mestre, pelo curso de Pós- Gradução em Engenharia Mecânica - Área de concentração: Dinâmica de Máquinas e Sistemas.

Orientador: Prof. Dr. Glauco Augusto de Paula Caurin.

SÃO CARLOS 


\section{DEDICATÓRIA}

Aos meus pais e meus irmãos, pelos exemplos de pessoa que sempre procurei seguir e pelo amor incondicional. 


\section{AGRADECIMENTOS}

Ao pessoal do Laboratório de Mecatrônica, especialmente ao Ricardo, Kleber, Bruno, Poliane, Kelen, Luíza, Leonardo, Martins, Belini, Maciel e prof. Adriano, fundamentais para minha pesquisa se tornar realidade.

Ao Prof. Dr. Glauco Augusto de Paula Caurin, pela oportunidade, orientação e confiança.

Ao Henrique, pelo carinho e por apoiar meus sonhos.

Aos meus amigos, Hilano, Denise, Patrícia, Luciana, Alice, Tatu, Paula, Fernando, Bíolis e Rodrigo que, de alguma forma, contribuíram para este trabalho. 
RESUMO

ITO, G. G. Sistema mecatrônico para reabilitação pós-fratura da extremidade distal do rádio. 2011. 89p. Dissertação Mestrado - Escola de Engenharia de São Carlos, Universidade de São Paulo, São Carlos.

A fratura da extremidade distal do rádio é o tipo de lesão mais comum encontrada nos departamentos de emergência ortopédica. Requer reabilitação efetiva que pode ser feita com contribuições de tecnologias atuais. Para isto foi construído um sistema mecatrônico móvel e interativo a partir de conhecimentos de especialistas na área da saúde e engenharia. O sistema foi testado em trinta pessoas saudáveis, sendo eles profissionais das áreas citadas e a população mais acometida: homens jovens e mulheres pós- menopausa. Os dados obtidos foram analisados, assim como as pistas sociais apresentadas pelos participantes. Após os testes todos responderam um questionário para avaliar o sistema. Os resultados mostraram que o sistema cumpre grande parte dos requisitos necessários para a reabilitação, mas precisa de melhorias.

Palavra-chave: Tecnologia de reabilitação, terapia da mão, fratura do rádio. 


\begin{abstract}
ITO, G. G. Mechatronic system for rehabilitation after fracture of distal radius. 2011. 89 p. Dissertação Mestrado - Escola de Engenharia de São Carlos, Universidade de São Paulo, São Carlos.
\end{abstract}

Distal radius fracture is the most common type of injury found in emergency of orthopedic department. It requires effective rehabilitation that can be made with contributions of current technologies. For this, a mobile and interactive mechatronic system was built from the expertise of specialists in healthcare and engineering. The system was tested in thirty healthy people, the professionals of these areas and the population most affected: young men and postmenopausal women. The data and the social cues presented by the participants were analyzed. They answered a questionnaire to evaluate the system. The results showed that the system meets many rehabilitation requirements, but improvements are necessary.

Key-words: Rehabilitation technology, hand therapy, fracture of the radius. 


\section{LISTA DE FIGURAS}

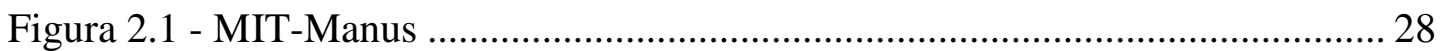

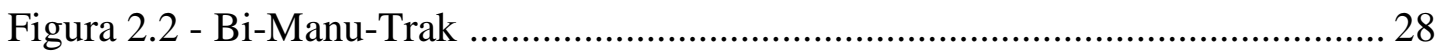

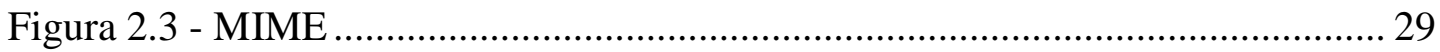

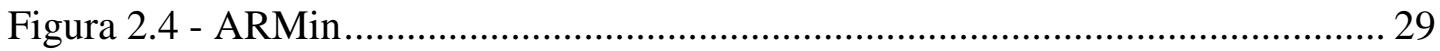

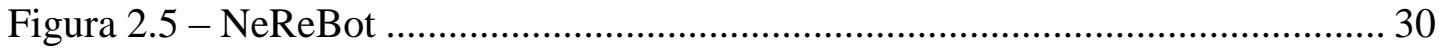

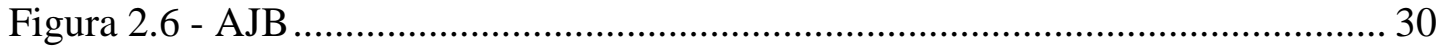

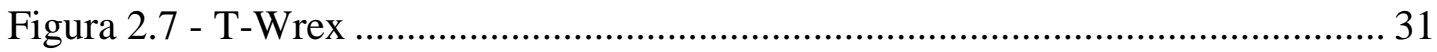

Figura 2.8 - Cyber Glove e Rutgers Master II ….................................................. 32

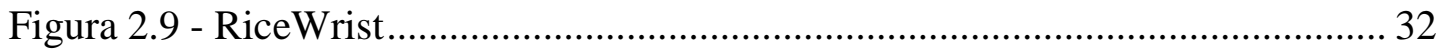

Figura 2.10 - Sistema do Imperial College …....................................................... 33

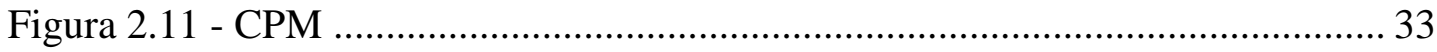

Figura 3.1 - Goniometria do antebraço: pronação (a), supinação (b) ……................. 39

Figura 3.2 - Goniometria radio-cárpica: flexão (a), extensão (b) ............................. 40

Figura 3.3 - Goniometria radio-cárpica: desvio ulnar (a), radial (b) ....................... 41

Figura 4.1 - Conceito do mecanismo da manopla .................................................. 50

Figura 4.2 - Projeto do protótipo: desenho (a), início da construção (b) ................... 51

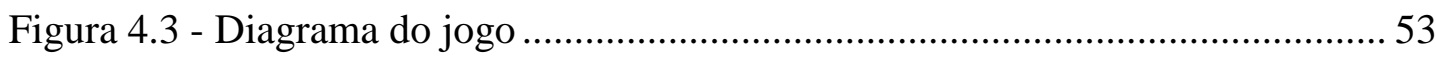

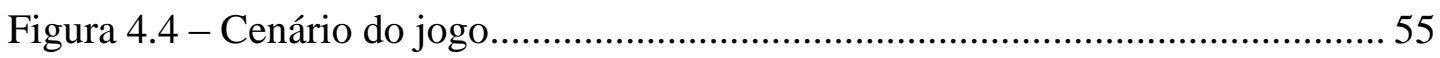

Figura 5.1 - Protótipo: posição neutra (a), posição pronada (b) ............................... 56 
Figura 5.2 - Hardware apoiado sobre mesa com opção de regulagem de altura 57

Figura 5.3 - Jogo "Pong": tela inicial (a), jogo em andamento (b) 58

Figura 5.4 - Uso do sistema em domicílio 59

\section{LISTA DE TABELAS}

Tabela I - Dados antropométricos de adultos da população britânica

Tabela II ANEXO C

Tabela III 61

\section{LISTA DE GRÁFICOS}

Gráfico 3.1 - Processo de fluxo- sensação.................................................................. 46

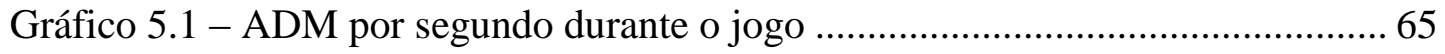




\section{LISTA DE SIGLAS E ABREVIATURAS}

ADM

AJB

AVD

AVE

CPM

EPOS

GdL

MIME

MIT

NeReBot

PO

RV

SBTM
Amplitude de Movimento

Active Joint Brace

Atividade de Vida Diária

Acidente Vascular Encefálico

Continuous Passive Motion

Easy-to- use Positioning

Grau de Liberdade

Mirror-image motion enabler

Massachusetts Institute Technology

Neuro-rehabilitation-robot

Pós- operatório

Reabilitação Virtual

Sociedade Brasileira de Terapeutas da Mão 


\section{SUMÁRIO}

p.

RESUMO

6

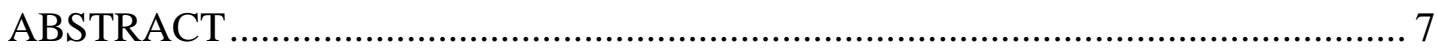

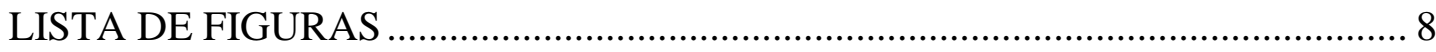

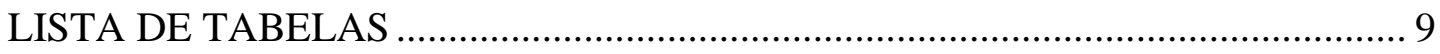

LISTA DE SIGLAS E ABREVIATURAS ........................................................... 10

1 INTRODUÇÃ

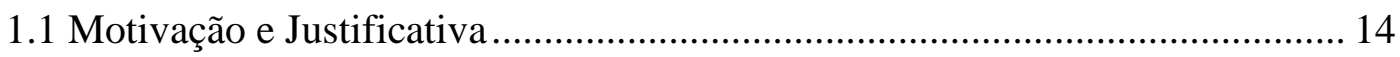

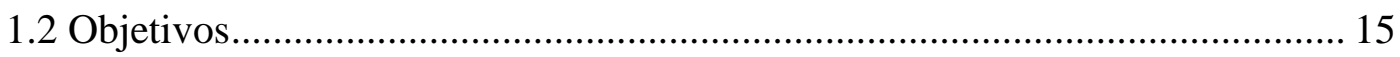

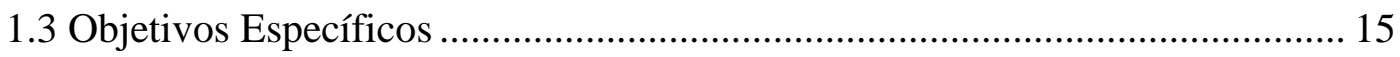

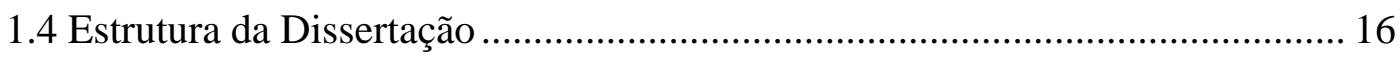

2 REVISÃO DA LITERATURA................................................................... 17

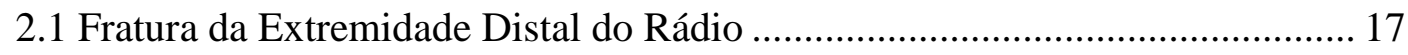

2.2 A Terapia Ocupacional e o Lúdico ............................................................ 19

2.3 Jogos Eletrônicos e Reabilitação Virtual ...................................................... 23

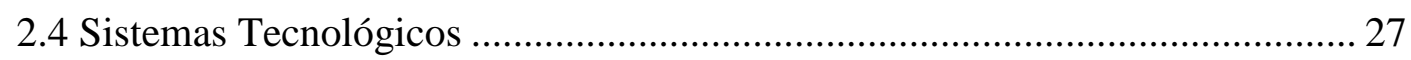

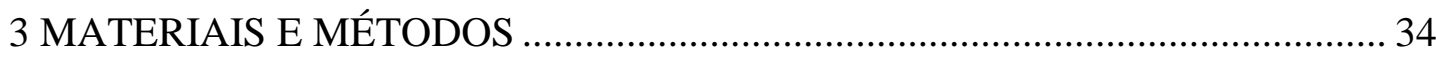

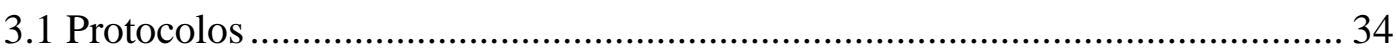


3.2 Premissas de Projeto Mecânico 42

3.2.1 Ergonomia 42

3.2.2 Materiais 44

3.3 Premissas de Integração de Sistemas 45

3.4 Jogos Computacionais 45

4 PROJETO DESENVOLVIDO 50

4.1 O Projeto Mecânico. 50

4.2 O Projeto Eletrônico 52

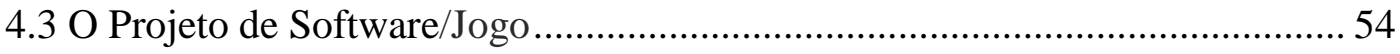

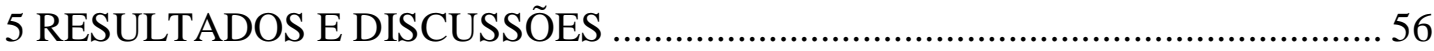

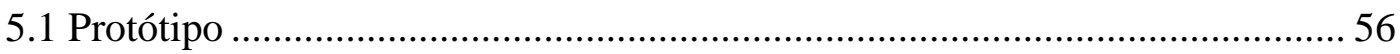

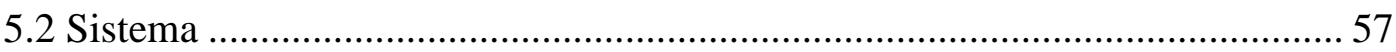

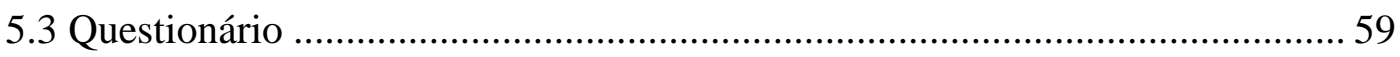

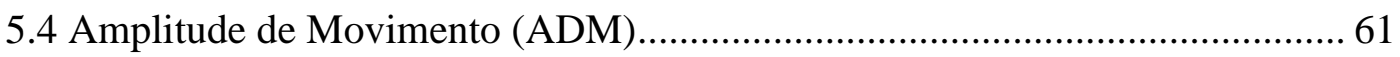

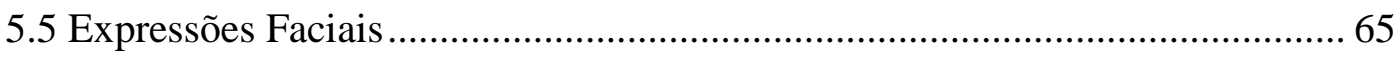

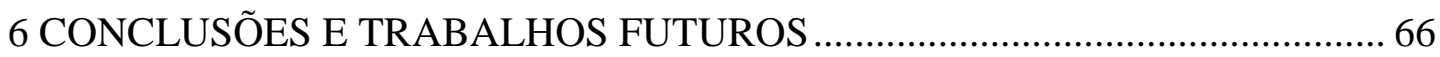

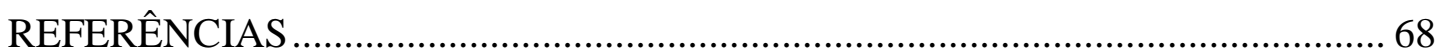

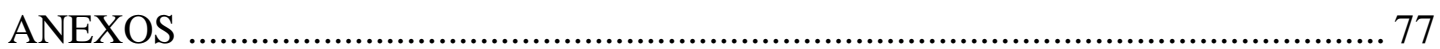

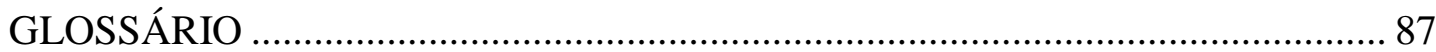




\section{Capítulo 1}

\section{1 - Introdução}

O capítulo inicial oferece um panorama da problemática onde atua; a fratura da extremidade distal do rádio e sua reabilitação, além da motivação e justificativa, objetivo, objetivos específicos e a estrutura da dissertação dividida em subtópicos.

Fratura da extremidade distal do rádio, na região do punho, é o tipo mais comum de lesão ortopédica encontrada nos departamentos de emergência. Esta região é vulnerável por ser o instrumento primário da ocupação, defesa e expressão humana (HUNTER et al., 2002). Acomete todas as idades, principalmente homens jovens e mulheres pós-menopausa.

Para haver consolidação óssea, há a necessidade de imobilização que pode durar de seis a oito semanas (COTRAN et al., 2000). Por se tratar de uma fratura que pode envolver a articulação, o punho, na maioria dos casos, permanece imóvel durante o tempo de consolidação. Após a liberação, percebe-se uma diminuição de amplitude de movimento (ADM) outras complicações. Consequentemente, há a diminuição da função do membro superior para atividades cotidianas e laborais, da auto-estima e das relações sociais.

A complexidade da anatomia desta região e de consequências causadas por esta lesão torna necessária a reabilitação do paciente em um serviço de Terapia Ocupacional especializado, com objetivos que levam em conta não apenas aspectos fisiológicos e anatômicos, mas também psicológicos e sociais. O diálogo entre o 
cirurgião da mão, terapeuta da mão e paciente, necessita de uma linguagem única, conhecida e facilmente acessada. De acordo com Ferrigno (2007), a tríade formada pelos envolvidos no processo tem papel fundamental na boa recuperação e eficácia do tratamento.

O terapeuta necessita fazer avaliações para acompanhar o progresso do paciente ou a possível necessidade de mudança de conduta, que precisa ser discutida com o médico. Um dos norteadores é o grau de ADM, medido com o auxílio de goniômetro. Este processo de avaliação não possui total confiabilidade e os resultados não são facilmente acessados e visualizados pelos envolvidos. Soma-se a este problema, a alta quantidade de pessoas atendidas ou em filas de espera, o longo tempo de tratamento dos casos com complicações e, para alguns, a dificuldade de ir aos centros de reabilitação especializados.

Apenas a reabilitação ambulatorial não é suficiente para o progresso do paciente. Este tem que dar continuidade ao tratamento em seu domicílio. Neste momento, não há o acompanhamento do especialista e muitas vezes o exercício é feito de uma maneira diferente da ideal ou não é realizado por diversos motivos, entre eles, o entendimento do procedimento e das consequências, o isolamento ou a desmotivação.

\section{1 - Motivação e Justificativa}

As tecnologias existentes atualmente podem contribuir para diminuir as dificuldades da área da saúde. Os bons resultados da aplicação de sistemas tecnológicos em reabilitação, principalmente de pacientes pós- Acidente Vascular Encefálico (AVE) (MASIA et al., 2007; HESSE et al., 2003; BURGAR et al., 2000; 
NEF et al., 2007; MASIERO et al., 2007; Stein et al.,2007; SANCHEZ et al., 2006; MERIANS et al., 2002; GUPTA et al., 2008; DOVAT et al., 2008), servem como base para que outras possibilidades sejam exploradas.

\section{2 - Objetivo}

Desenvolver, a partir de conhecimentos de especialistas na área da saúde e da engenharia, um sistema mecatrônico móvel e interativo como ferramenta de auxílio na reabilitação de pessoas que sofreram fratura da extremidade distal do rádio.

\section{3 - Objetivos Específicos}

1. Construir um sistema mecatrônico, baseado em conhecimentos de especialistas, capaz de aplicar o protocolo de tratamento de fratura da extremidade distal do rádio do Centro de Reabilitação de Mão de Indiana (CANNON et al., 2001), além de avaliar a ADM e a freqüência do uso, motivado com jogo eletrônico.

2. Analisar o sistema comparando dados da avaliação de ADM antes e durante o jogo.

3. Avaliar o sistema baseando-se em testes feitos em especialistas e possíveis usuários.

4. Verificar dados emocionais do jogador durante o uso do sistema. 


\section{4 - Estrutura da Dissertação}

O Capítulo 2 apresenta a revisão bibliográfica. Os materiais e métodos são apresentados no Capítulo 3. O Capítulo 4 descreve o projeto desenvolvido detalhadamente. Os resultados e discussões estão no Capítulo 5. No Capítulo 6 foi feita a conclusão e pensado os trabalhos futuros. Seguem as referências, glossário e anexos. 


\section{Capítulo 2}

\section{2 - Revisão Bibliográfica}

A revisão bibliográfica preocupou-se primeiramente em situar a problemática principal; a fratura da extremidade distal do rádio. No segundo subtópico, mostra de que maneira a Terapia Ocupacional atua na reabilitação, destacando as dificuldades encontradas e a influência do lúdico.

Os jogos eletrônicos e a internet fazem parte cada vez mais do cotidiano das pessoas. Através deles a reabilitação vem se diversificando. Foram pesquisados, no terceiro subtópico, diversos trabalhos de reabilitação virtual e sistemas tecnológicos utilizados como auxiliares na terapia. Em grande parte deles, os hardwares e softwares foram desenvolvidos de acordo com as necessidades, apresentados no quarto subtópico.

\section{1 - Fratura da extremidade distal do rádio}

Fraturas da extremidade distal do rádio são usualmente definidas como aquelas que acometem este osso dentro de três centímetros da articulação radiocarpal (HANDOLL \& MADHOK, 2003). Brinker \& O’Connor (2004) fizeram um levantamento das lesões encaminhadas para o Hospital Ortopédico do Texas, apresentando o antebraço como o local de acometimento mais comum (25\%), seguido da mão (19\%) e do pé (13\%). No Brasil, foi realizado um estudo no serviço público de ortopedia do hospital de Fortaleza (BRAGA Jr. et al., 2005), onde a 
fratura da extremidade distal do rádio foi responsável por $7 \%$ de todos os atendimentos, sendo a fratura mais comum.

O punho é a comunicação entre a mão e o antebraço. Segundo Saringer et al. (1999), sem essa amplitude de movimento, as atividades de vida diária (AVD`s), como virar chave e maçaneta de porta ou segurar talheres para alimentar- se, ficam severamente comprometidas. O punho deve ser móvel, permitindo o posicionamento da mão para as AVD’s, trabalho, recreação e comunicação. Deve ser estável, permitindo a força para carregar, arremessar e pegar. A mobilidade e a estabilidade da articulação dependem de ligamentos intactos, ossos alinhados e tecidos moles preservados.

Após a consolidação da fraturas, pode haver complicações que inclui rigidez dos dedos pela imobilização com gesso, infecção dos pinos e lesão de tecidos moles causados pela fixação externa ou fixação percutânea. $\mathrm{O}$ alinhamento do carpo em relação à superfície articular da extremidade distal do rádio após a cura também pode ser um importante fator nos resultados do tratamento. Dores, edema e perda de função física podem ocorrer tendo impacto na função social e emocional. Distrofia Simpático Reflexa ou Síndrome Complexa Regional é uma consequência debilitante que ocorre entre $1 \%$ e $20 \%$ dos pacientes com esta fratura (LIPS et al., 2010). As complicações também incluem neuropatia, consolidação viciosa, encurtamentos de partes moles, ruptura do tendão e artrose rádio- ulnar e rádio- cárpica.

Chen \& Jupiter (2007) relataram uma distribuição bimodal das fraturas da extremidade distal do rádio que consiste em um grupo mais jovem que sustenta relativamente trauma de alta energia na extremidade superior e um grupo de idosos que sustentam ambas as lesões de alta e baixa energia. Entre 15 e 39 anos, a 
população masculina é 1.4 vezes mais acometida. Em contraste, entre 60 a 94 anos, mulheres são 6.2 vezes mais acometidas que homens (SINGER, 1998). Isso demonstra a maior fragilidade do osso pós menopausa, resultado do desuso e da osteoporose (O’NEILL, 2001). Lips et al. (2010) define a relação de uma fratura de punho prévia com subsequentes fraturas osteoporóticas em outras regiões. Nas mulheres, o risco de uma fratura de quadril aumenta 1,4- 1,8 vezes se havia uma fratura no punho anteriormente. Conforme aumenta a expectativa de vida, a incidência de fraturas radiais distais é esperada aumentar também. Com base em cálculos a partir de dados do plano de saúde Medicare, o risco de uma mulher branca sustentar uma fratura do antebraço distal foi estimado em $6 \%$ até a idade de oitenta anos e 9\%, em idade de 90 anos (CHEN \& JIPITER, 2007).

Fratura e AVE são as causas mais comuns de dificuldades em ADM do punho e requerem exercícios específicos para tornar a articulação funcional novamente. A reabilitação de fratura costuma ser longa, onerosa, comumente dolorosa e inflexível, quanto ao local e horário, para o paciente e para o terapeuta. Muitas são baseadas no conceito de repetição ou o estímulo muscular para alcançar a ADM que pode resultar em perda da motivação durante o tratamento.

\section{2 - A Terapia Ocupacional e o lúdico}

A Terapia Ocupacional utiliza a atividade como um meio para reabilitar. A atividade pode ser de diversos tipos, por exemplo, jogos. Porém, para que seja uma prática terapêutica ocupacional, algumas considerações precisam ser observadas. Primeiramente a definição da profissão feita pela Associação de Terapeutas Ocupacionais do Estado de São Paulo: 
“...O Terapeuta Ocupacional profissionalmente qualificado envolve o paciente em atividades destinadas a promover o restabelecimento e o máximo uso de suas funções com o propósito de ajudá-los a fazer frente às demandas de seu ambiente de trabalho, social, pessoal e doméstico e a participar da vida em seu mais pleno sentido..." (ATOESP, 2010).

A palavra "Atividade" é definida no dicionário (RIOS, 2010): "1. Qualidade ou estado ativo. 2. Diligência, prontidão. 3. Ocupação de uma pessoa. 4. Profissão, modo de vida. 5. Capacidade de agir. Antônimo: inatividade".

Apesar do conceito apresentado, atividade possui significados mais amplos que devem ser discutidos. Em Quarentei (2007) a vida pode ser definida por ela: “A vida é um continuum incessante de atividades", onde não são apenas realizações de tarefas, mas estão ligadas às necessidades e a aspectos subjetivos. Exemplificando, as atividades no contexto de reabilitação de uma fratura estão ligadas à necessidade de reabilitação física e aos aspectos subjetivos; sentimentos, crenças, atitudes, valores, emoções, percepções e sentidos.

Segundo Quarentei (2001), as diferenciações, a multiplicidade, a singularização se dá na atividade e não apenas entre diferentes atividades. Há fazeres que são efetuações da exclusão, da submissão, da repetição vazia e mortífera. O Terapeuta Ocupacional procura aumentar a potencialidade das pessoas. Pretende oferecer o que ilumina o olhar e não o que apaga.

Francisco (2001) atribui a três concepções a formação de processos de Terapia Ocupacional. A primeira é a humanista, onde o processo acontece de forma espontânea, na situação entre terapeuta e cliente, por meio da atividade. A segunda, concepção positivista, o processo é um artifício de rígidas condições em que se 
desenvolve às quais o paciente tem de adaptar-se. A terceira, concepção dialética, o processo é por definição transformador e questionador do contexto em que se efetiva. Seguindo o pensamento desta última concepção, Simões Jr. (1985) traduziu o pensamento de Marx; não é a consciência dos homens que determina o seu ser, mas ao contrário, é o seu ser social que determina sua consciência. Portanto, segundo Francisco (2001), o atendimento terapêutico ocupacional ideal não deve estar voltado apenas para a disfunção, e sim para o homem como ser essencialmente social, o significado da terapia "leva o homem a lidar com sua realidade de vida, podendo assim promover a transformação de si mesmo e do meio social no qual está inserido". Deste modo, na terapia ideal, a atividade é a base real do tratamento, o indivíduo traz suas ações, conceitos, experiências com a lesão, doença, e o terapeuta favorece as reflexões e discussões das questões conflitivas.

O tratamento ambulatorial de uma fratura na região do punho necessita de continuidade com exercícios domiciliares específicos, caracterizando também, de certo modo, uma concepção positivista. Apesar de ser indicado, possui diversos problemas práticos. Dentre eles, segundo Barbosa et al. (2009), pode-se citar a adesão e/ou obediência a este tipo de tratamento, a variação do nível sócio cultural dos pacientes e a obediência às instruções. A cooperação e a satisfação do paciente com o programa de exercícios domiciliares são importantes para a o sucesso da intervenção (CHEN et al., 1999).

O sucesso da terapia pode ser atingido com atividades de lazer que, como expõe De Masi (2000), vem ao encontro da satisfação das necessidades qualitativas humanas (convivência, introspecção, brincadeira, amizade, amor), no sentido de reduzir as distâncias que segregam determinados grupos sociais. A atividade de lazer 
foi entendida como uma característica evolucionária que preparava os jovens para a competência da vida adulta, como também um comportamento adulto necessário para relaxar e recriar o organismo, a fim de conseguir realizar o trabalho (MENDES \& MELO, 2009). Qualquer manifestação em que haja alegria, divertimento e prazer, mesmo que haja momentos de tensão e conflitos, caracteriza-se como atividade lúdica. O lúdico pode contribuir de forma significativa para o desenvolvimento do ser humano, seja ele de qualquer idade, auxiliando não só na aprendizagem, mas também no desenvolvimento social, pessoal e cultural, facilitando no processo de socialização, comunicação, expressão e construção do pensamento (MAURÍCIO, 2010). No dicionário (RIOS, 2010), lúdico apresenta-se relativo a jogo.

Huizinga (1990) define o jogo como "fenômeno da cultura que transcende as necessidades imediatas da vida". A criatividade presente nesta atividade relaciona-se com a possibilidade de manipulação da realidade, não sendo um fenômeno da vida cotidiana.

“...Todo jogo acontece no campo do imaginário, construindo uma nova realidade, acessada e compreendida eminentemente pelos sujeitos que participam de sua ação. Suspenso da realidade corrente, de uma lógica racionalista e utilitarista, o jogo está impregnado de desejos individuais e de significações culturais, ou seja, coletivas e sociais... “ (MELO et al., 2010).

Durante o jogo o usuário é afetado por sentimentos e emoções. Para Woodworth (1973) "sentimento e emoção são estados individuais passageiros, associados a motivos". Ele considera que sentimentos são estados conscientes que variam em espécie e intensidade. As emoções são estados individuais exaltados, relacionados ao sentimento, à preparação motora para a reação, ao estado orgânico e 
ao tipo de situação que a desencadeia. Durante o jogo, percebemos pistas sociais (relatos verbais, comportamentos e mudanças fisiológicas) que indicam os estados emocionais (BRAGHIROLLI et al., 1997).

\section{3 - Jogos eletrônicos e Reabilitação Virtual (RV)}

Os jogos eletrônicos podem ser classificados como um tipo de mídia condizente com a atualidade, pois são atividades que contam cada vez mais com avanços tecnológicos, possibilitam novos tipos de interação presencial ou virtual e oferecem uma contingência de rapidez entre estímulo e resposta. De acordo com Suzuki et al. (2009), eles estão cada vez mais presentes nas atividades de lazer e no desenvolvimento de habilidades. Apresentam uma grande diversidade, desde os que requerem atividade eminentemente sensório-motora, até aqueles que exigem do jogador grande capacidade estratégica e de entendimento de regras. Bracht (2003) destaca ainda características como a competição; a busca do rendimento físicotécnico; objetificação do recorde; a racionalização do treinamento dos movimentos; especialização dos papéis; quantificação dos resultados; e controle minucioso da gestualidade do corpo.

Gentile et al. (2007) sugeriram que os jogos podem utilizar ao menos três características para exercitar o indivíduo- o conteúdo, a estrutura e a mecânicacada um deles parecem ter efeitos específicos. A mecânica do jogo apresenta-se relacionada a melhoras em habilidades específicas como coordenação olho-mão. A estrutura dos jogos apresenta-se relacionada a melhoras na atenção visual. Além disso, o conteúdo dos jogos reflete no comportamento dos jogadores na vida real. Os jogos não são inerentemente bons ou maus, podendo ter efeitos negativos e positivos 
dependendo da mensagem que passa; positiva, negativa ou neutra. A mensagem do jogo "Pong", o qual foi desenvolvido neste trabalho, caracteriza- se como neutra.

Os jogos eletrônicos tradicionais utilizam controle através de botões apertados por usuários. Contrapondo a este sedentarismo, uma nova geração de vídeo games como Sony PlayStation ${ }^{\circledR}$, EyeToy ${ }^{\mathrm{TM}}$, Nintendo Wii ${ }^{\mathrm{TM}}$ e Kinect $^{\mathrm{TM}}$ para Xbox provém o comportamento fisicamente ativo, utilizando movimentos do corpo para controlar as atividades na tela.

Segundo Halton (2008), assim como a tecnologia avança, os métodos da área da saúde evoluem. Um exemplo é o uso da Reabilitação Virtual (RV) que pode ser descrita como uma simulação do mundo real através de um computador e vivenciada por uma interface Homem-Máquina. A RV é capaz de estimular múltiplas modalidades sensoriais e, além disso, cria uma interface para o paciente interagir. A RV também oferece ao terapeuta a possibilidade de individualizar o programa de reabilitação às necessidades do paciente e a possibilidade de continuidade do tratamento independente do terapeuta, armazenando dados para análise.

Madisson et al. (2009) pesquisou o uso de RV e jogos computacionais em reabilitação motora na literatura. Esta técnica mostrou-se como uma forma efetiva de prover diversão e motivação, podendo ser um facilitador do processo de tratamento. Ainda beneficiou o equilíbrio, a resistência, a destreza, a velocidade e a ADM.

O fenômeno dos jogos eletrônicos tem estreita relação com o uso da internet, uma vez que grande parcela dos jogos existentes pode ser praticada por essa via. A internet, segundo Gáspari \& Schwartz (2005), representa hoje o maior repositório de informações disponíveis a qualquer pessoa que a acesse de qualquer parte do mundo. 
A internet introduziu uma nova forma de aquisição de informações, pensamento, busca por conhecimento, comunicação social e lazer.

A internet atingiu rapidamente vários tipos de pessoas, inclusive as da terceira idade. A pesquisa do Instituto Brasileiro de Geografia e Estatística (IBGE) de 2009 revela que o contingente de pessoas de mais de 60 anos soma cerca de 21 milhões. De acordo com Chen \& Jupiter (2007), juntamente com o crescimento da população idosa é uma tendência para os indivíduos neste segmento ter uma vida mais ativa. $\mathrm{O}$ idoso vivencia o rebaixamento da auto-estima e as inseguranças quanto à identidade refletem-se na autonomia, liberdade, convívio social afetado não apenas a freqüência como, também, a qualidade dos relacionamentos interpessoais e dos vínculos afetivos no grupo. O idoso usuário da rede mundial de computadores tem benefícios psicológicos importantes, tais como: prevenção da depressão e do isolamento social, especialmente os limitados fisicamente, e manutenção dos níveis cognitivos (MIRANDA \& FARIAS, 2009). Com maior acesso à informação e à participação ativa em diferentes vivências, marca da sociedade globalizada, o idoso vem tendo oportunidades, nos mais diversos âmbitos, de ressignificar sua existência, sua aprendizagem, sua importância como cidadão detentor de direitos e garantias legais, seu envelhecimento, sua própria velhice e os níveis de sua efetiva participação dentro da sociedade. (GÁSPARI \& SCHWARTZ, 2005).

Pela internet, idosos da cidade de São Paulo receberam programas de exercícios físicos semanalmente, fornecido pelo educador físico, e realizavam o solicitado nos parques da cidade. O método mostrou-se efetivo para reduzir a pressão arterial e melhorar a composição corporal dos participantes (NUNES et a.l, 2006). 
Costa et al. (2005) comprovaram a efetividade da internet como forma auxiliar de tratamento para perda de peso. Os 532 participantes de um estudo realizado por esses autores - adultos, com sobrepeso e idade média não relatada foram acompanhados durante 13 meses, e enviaram diariamente, via internet, uma lista com os itens sobre a sua ingestão de alimentos e a massa corporal pesada toda semana. O índice de massa corporal médio foi reduzido de $30,9 \mathrm{~kg} / \mathrm{m} 2$ para 28,2 $\mathrm{kg} / \mathrm{m} 2$, e o peso corporal médio, de 82,3 para $75 \mathrm{~kg}$.

Johnson et al., 2008, analisaram dois grupos de RV utilizando jogos e internet. Um jogando contra o computador e outro contra um oponente real em outro continente. Este último mostrou-se mais interessante, divertido, onde o paciente passou mais tempo na atividade.

Vanaken et al. (2010) investigaram como suporte social pode ser benéfico para o paciente. A interação social entre jogadores aumenta a motivação do paciente em continuar treinando, além de permitir partilhar histórias, prover e receber suporte. Relatou a situação em que um paciente recebeu a visita de um membro da família, o neto. Este auxiliou a reabilitação do avô jogando com ele, tornando o exercício mais agradável. Usando a internet, os co-jogadores podem estar distantes, permitindo os familiares a interagir virtualmente.

Segundo Butler (2010), há poucas pesquisas de uso da RV em reabilitação de lesões ou desordens músculo- esqueléticas. Sveistrup et al. (2003) reportaram o uso de um programa de RV em pacientes com ombro rígido. Depois de seis semanas de treino, mostraram $20 \%$ de melhora em flexão, abdução e rotação de ombro.

A dor é subjetiva e influencia no tratamento. Para avaliar como a RV pode interferir neste aspecto, trinta e nove pacientes que sofreram queimaduras foram 
tratados com RV em um dia e outro com reabilitação convencional. Ao final de dez minutos de movimentação ativo-assistida com auxílio de um terapeuta ocupacional ou fisioterapeuta, pacientes responderam uma escala de avaliação analógica de dor de 0 a 100 (onde 0 representa sem dor e 100 a máxima dor). A ADM foi avaliada antes e depois da terapia. A RV reduziu em média 37\% da dor e melhorou a ADM em geral (CARROUGHER et al., 2009).

O uso da RV também foi feito em crianças com paralisia cerebral na pesquisa de Bryanton et al., 2006. A ADM de tornozelo foi medida com auxílio de um eletrogoniômetro. Os pacientes e seus pais foram instigados a comentar o interesse nos programas de exercícios. Durante exercícios de RV, foram relatados sentimentos de grande prazer e divertimento. Crianças completaram mais repetições com exercícios convencionais, mas a amplitude de movimento e o tempo de sustentação da posição de alongamento foram maiores durantes exercícios de RV.

\section{4 - Sistemas Tecnológicos}

Grande parte dos grupos de estudos utilizando sistemas tecnológicos na reabilitação é formada por pacientes pós Acidente Vascular Encefálico (AVE). Para isto, foram desenvolvidos hardwares específicos. Um dos primeiros é o MITMANUS (fig.2.1) desenvolvido por Kreb et al. (1998) no Massachusetts Institute Technology (MIT) para treino de movimentos de ombro e cotovelo. Posteriormente, desenvolveram um protótipo para punho, com três graus de liberdade (GdL's), onde o paciente move o hardware para alcançar alvos na tela do computador. O sistema possui controlador adaptativo, que avalia o desempenho da ADM e modifica a dificuldade e a assistência prestada para realizar a tarefa. (MASIA et al., 2007). 


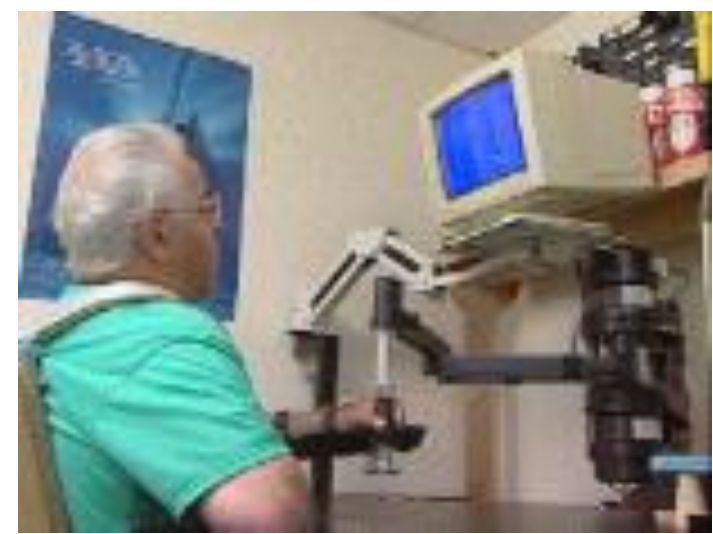

Figura 2.1- MIT-Manus (WILLIAMS, KREBS \& HOGAN, 2002)

Outro hardware desenvolvido na Universidade de Berlim é o Bi-Manu-Trak (fig. 2.2), com movimentos bilateral de prono- supinação de antebraço e flexoextensão de punho, ativos e passivos (HESSE, et al. 2003). Possui controle de impedância para garantir movimentos suaves. Após três semanas de exercícios com doze pacientes hemiparéticos crônicos, oito tiveram redução de espasticidade de movimento.

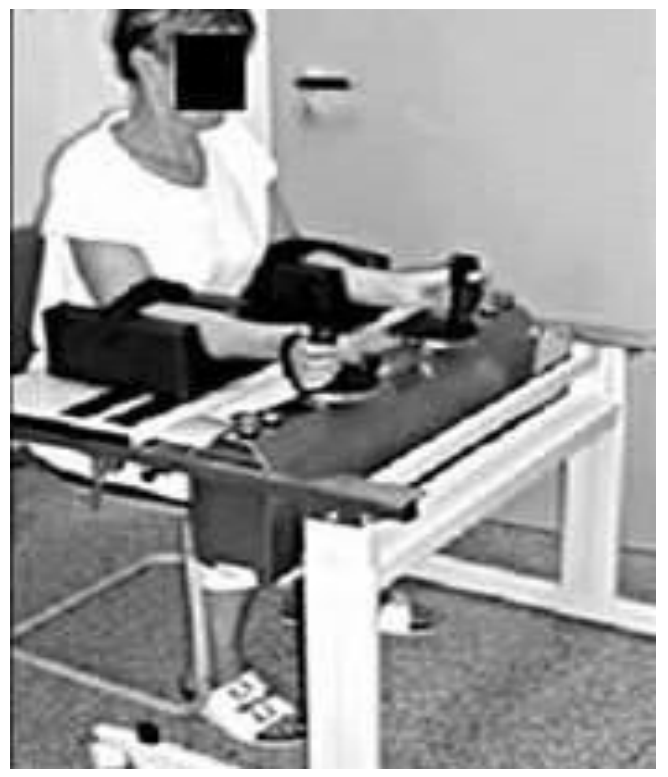

Figura 2.2- Bi- Manu- Trak (HESSE et al., 2006)

$\mathrm{Na}$ Universidade Standford, Califórnia, foi desenvolvido o mirror-image motion enabler (MIME) (fig.2.3) que consiste em um hardware com dois GdL's 
capaz de realizar os exercícios terapêuticos com abordagem bi-manual, utilizando imagem espelho (movimento do membro controlado ou auxiliado pelo membro contralateral do paciente) (BURGAR et al., 2000). Os testes com sujeitos normais mostraram melhores resultados com simulações de casos de hemiplegia flácida.

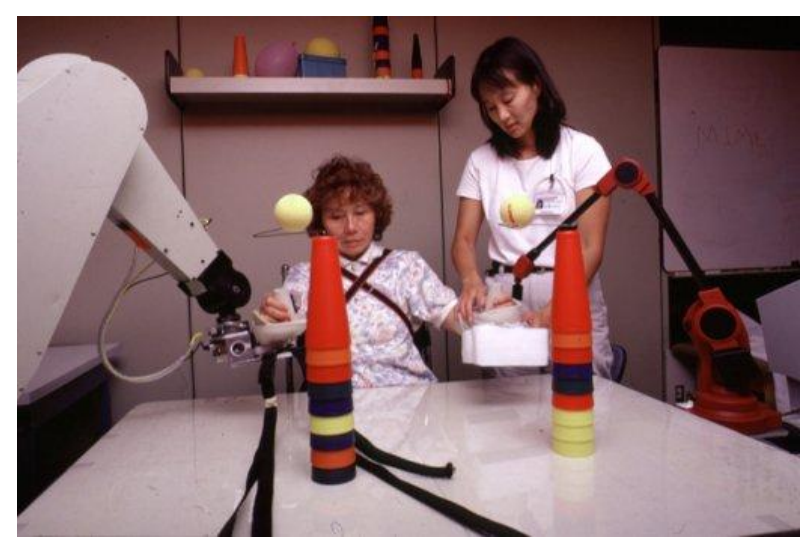

Figura 2.3- MIME (BURGAR et al., 2000)

ARMin (NEF, et al. 2007) é um semi-exoesqueleto desenvolvido em Zurique para movimentos no ombro (3GdL's), cotovelo (1 GdL), antebraço (1GdL) e punho ( $1 \mathrm{GdL})$. Conta com sensores de posição, força e torque e auxilia nos movimentos de acordo com a necessidade do paciente (fig.2.4).
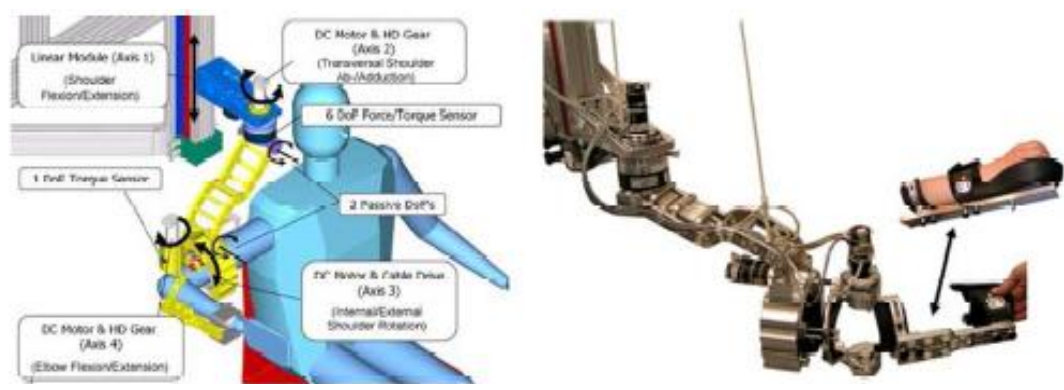

Figura 2.4- Sistema ARMin (NEF et al., 2007)

Na Universidade de Pádova, um robô de três GdL's chamado NeReBot (NEuro-REhabilitation-roBOt) (fig.2.5), foi confeccionado em alumínio e fios de 
nylon e obteve bons resultados funcionais com pacientes pós-AVE em fase aguda (MASIERO et al., 2007).

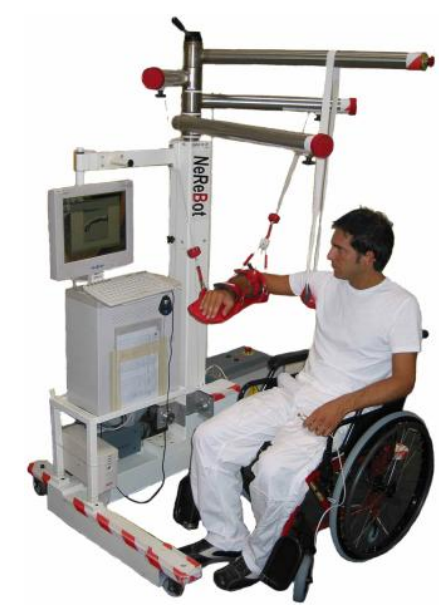

Figura 2.5- NeReBot (Masiero et al., 2007)

Stein et al. (2007), na Escola de Medicina de Harvard, Boston, utilizaram no exoesqueleto Active Joint Brace (AJB) (fig.2.6) dois controles por eletroneuromiógrafo em músculos flexores e extensores do cotovelo, construído no MIT. Obtiveram melhora de espasticidade e funcionalidade em todos os seis pacientes com hemiparesia crônica severa.

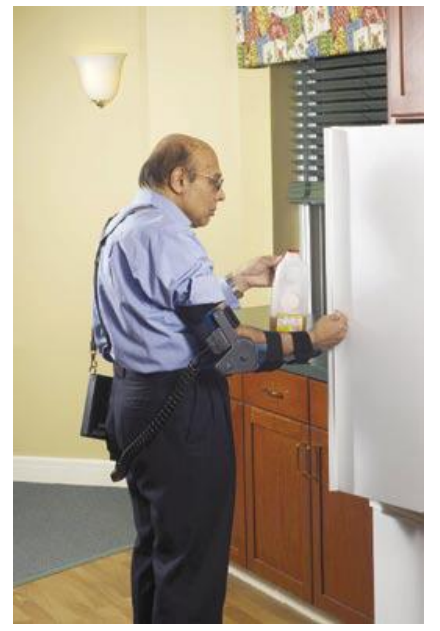

Figura 2.6- AJB (Halper, 2007) 
T-Wrex (Wilmington Robotic Exoskeleton) (fig.2.7), testado no Hospital Alfred I. Dupont para crianças (RAHMAN et al., 2006) e desenvolvido na Universidade da Califórnia (SANCHEZ et al., 2006), é um sistema composto por uma órtese, sensores de preensão e de posição e um software que simula atividades funcionais. Os pacientes e terapeutas podem visualizar gráficos de progresso que mostram a frequência do uso do aparelho, pontuações e o histórico do usuário em cada atividade.

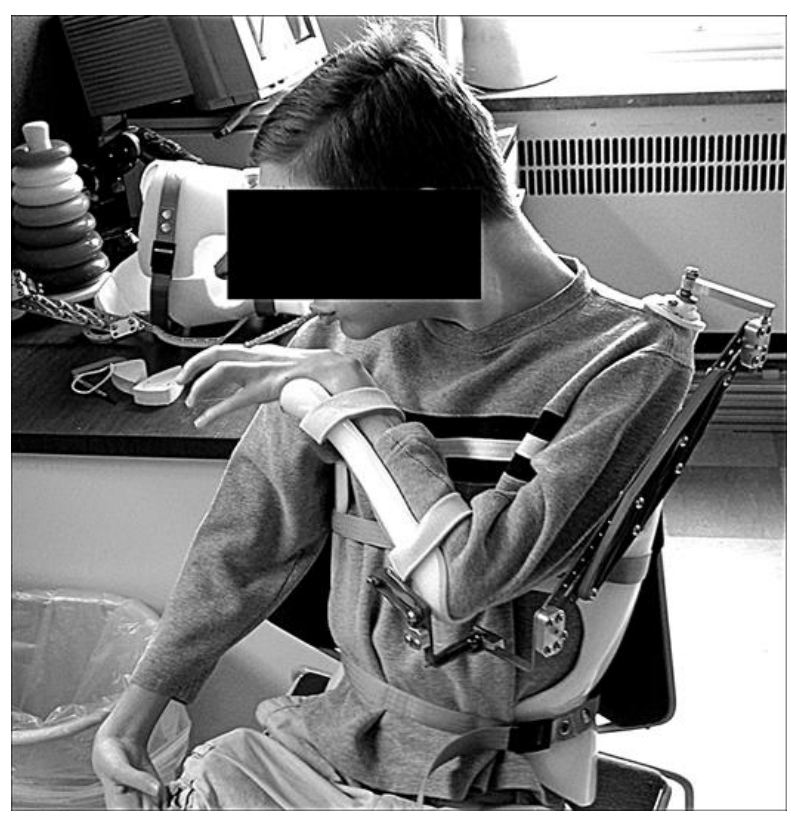

Figura 2.7- T-Wrex (Rahman et al., 2006)

O Rutgers Master II Glove e o Cyber Glove (fig.2.8) desenvolvidos por MERIANS et al. (2002) utilizam RV com quarto tipos de programas que treina amplitude de movimento, velocidade, movimento dissociado de dedos e força de dedos. 


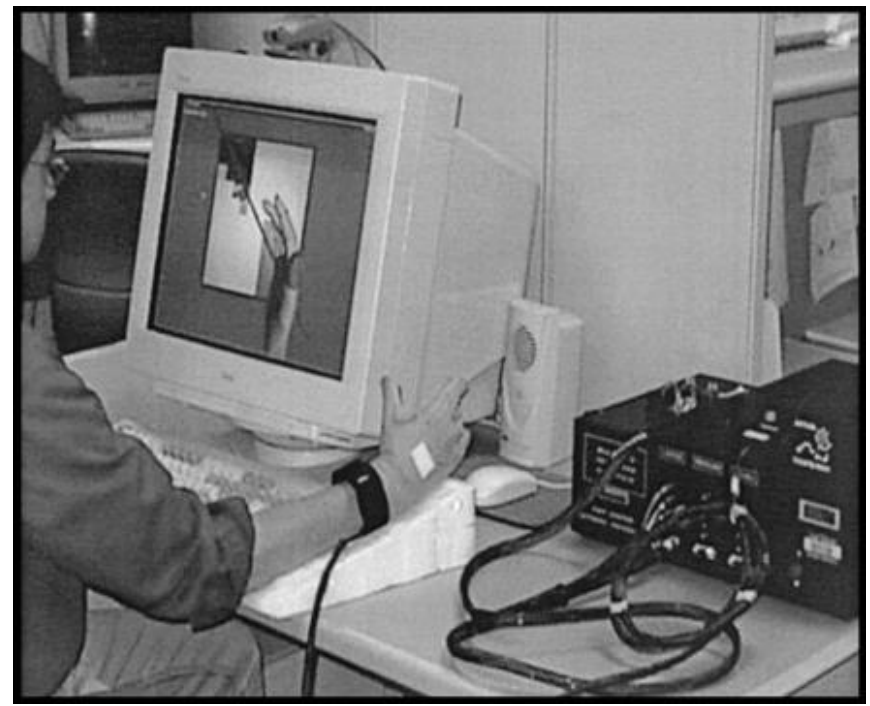

Figura 2.8- Cyber Glove e Rutgers Master II (Merians et al., 2002)

Em Houston, Texas, um sistema chamado RiceWrist (fig.2.9) possibilita reabilitação com movimentos do punho e antebraço, com controle de impedância e avaliando a amplitude de movimento (GUPTA et al., 2008).

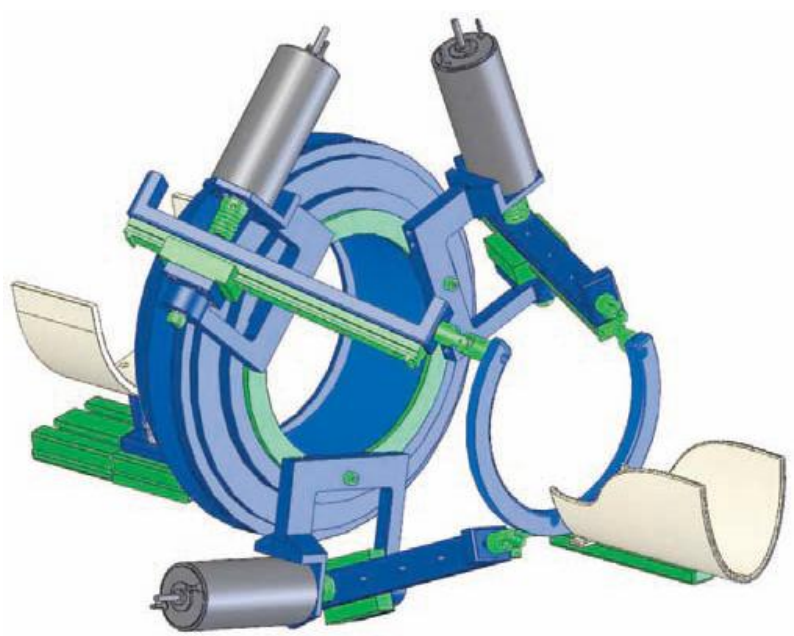

Figura 2.9- Desing mecânico do RiceWrist (Gupta et al., 2008)

No Imperial College em Londres, exercícios sistemáticos foram desenvolvidos para melhorar o desempenho funcional de dedos de pacientes pósAVE usando interface robótica (fig.2.10) (DOVAT et al., 2008). Utiliza atuadores a 
cabo, onde os movimentos de cada dedo é realizado de forma independente.

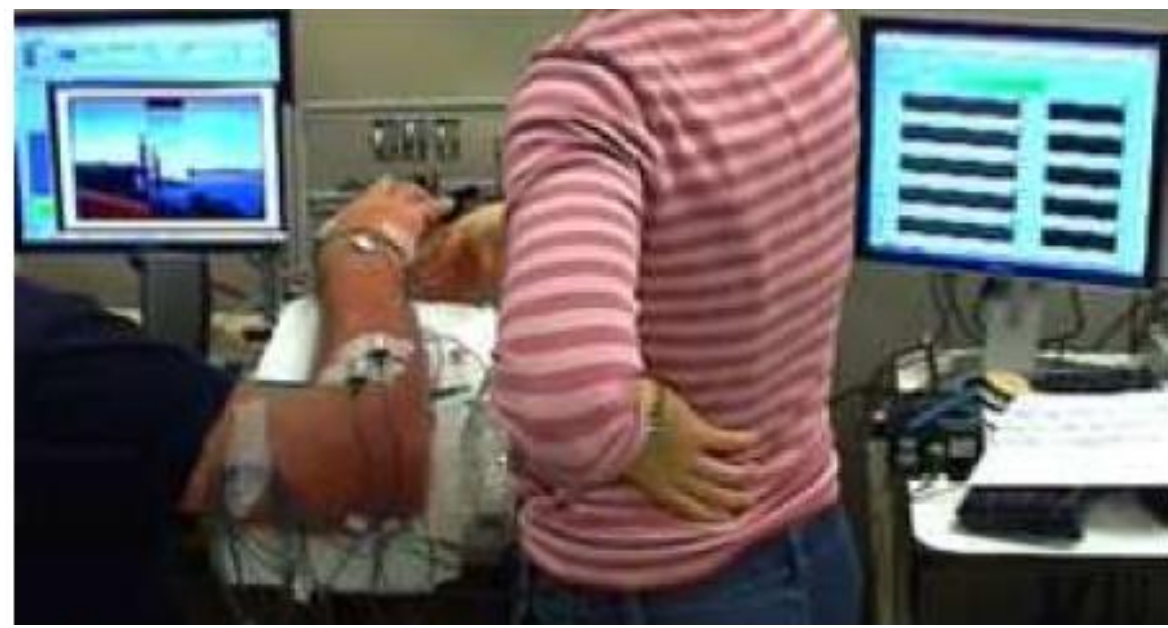

Figura 2.10- Sistema do Imperial College (Dovat et al., 2008)

O aparelho Continuous Passive Motion (CPM) auxilia exercícios de reabilitação. Alguns deles são específicos para fraturas da extremidade distal no rádio, como o patenteado em 1999 por Saringer \& Culhane (fig.2.11). Oferece apenas a fase da reabilitação de movimentação passiva do membro e não possui todos os GDL's.

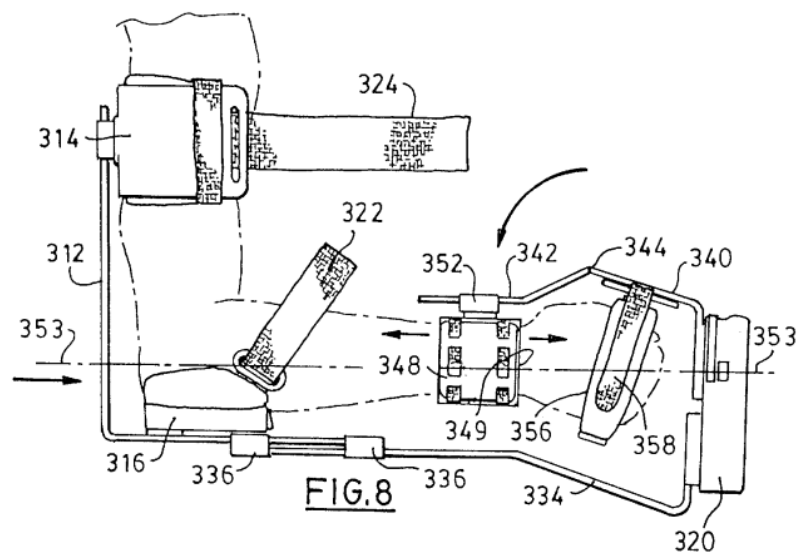

Figura 2.11- Aparelho CPM para pronação e supinação do antebraço (Saringer \& Culhane, 1999)

Não foi encontrado nenhum sistema específico para protocolos de reabilitação de fraturas de extremidade distal do rádio. Para a construção do hardware e do sistema em geral, alguns requisitos são necessários e expostos no próximo capítulo. 


\section{Capítulo 3}

\section{3 - Materiais e Métodos}

Neste capítulo, todos os detalhes do projeto e pesquisa são discutidos. Primeiramente serão apresentados os protocolos de reabilitação de fratura e de avaliações. Estes norteadores aliados à ergonomia foram os requisitos para a construção do projeto mecânico e de ferramentas computacionais, detalhados a seguir. Os jogos e o display levaram em consideração aspectos subjetivos, inerentes da Terapia Ocupacional. Por último, será mostrado como o sistema será aplicado e analisado.

\section{1 - Protocolos}

As formas de reabilitação são componentes essenciais na terapia. Segundo Decker e Losowyj (2009), movimentos repetitivos podem ajudar a melhorar a memória muscular, permitindo a rápida comunicação para controle muscular e movimentos finos.

Barbosa et al. (2009) levantaram vinte e dois estudos sobre reabilitações de fraturas da extremidade distal do rádio. Neles, o ganho de ADM de punho e dedos deve iniciar-se com movimentação ativa e progredir para movimentação passiva e mobilização articular. A movimentação ativa na reabilitação é quando o indivíduo usa a contração de seus músculos para realizar o movimento, e passiva quando há uma força externa aplicada. Os autores enfatizaram os movimentos de pronosupinação do antebraço (plano transversal), de flexão/ extensão (plano sagital) e 
desvios ulnar/radial (plano frontal) do punho. Porém, a literatura mostra uma tendência dos autores em utilizar os princípios gerais da reabilitação ao elaborar condutas terapêuticas. Os procedimentos utilizados não são bem documentados e atestados, dificultando a prática baseada em evidências pelos profissionais ao recuperarem esta lesão.

O manual de tratamento para Fisioterapeutas e Terapeutas Ocupacionais do Centro de Reabilitação de Mão de Indiana apresenta o seguinte protocolo para fratura da extremidade distal do rádio com consolidação auxiliada por fixador externo (CANNON et al., 2001) que serviu como modelo para projetar o sistema:

- 6 Semanas pós-operatório (PO): comumente, a fratura está cicatrizada a ponto de remover o fixador. Com a remoção, exercícios de movimentação ativa são iniciados na região do punho e antebraço por 10 minutos a cada $1-2$ horas. Fortalecimento pode ser iniciado com massa de silicone ou um exercitador de mão. Caso haja edema persistente ou o paciente relatar dor com os exercícios de resistência, o fortalecimento é postergado. Uma luva de compressão é efetiva para reduzir o edema.

- 7-8 Semanas PO: exercícios de movimentação passiva podem ser iniciados no punho e antebraço assim que o cirurgião atestar a cicatrização da fratura para suportar o alongamento passivo.

- 9 Semanas PO: uma órtese dinâmica pode ser incluída para aumentar a ADM. Fortalecimento progressivo do punho é iniciado com pesos de mão. Massa de 0,5 a $1 \mathrm{~kg}$ inicia o processo. Leve tração e a mobilização do punho podem ser realizadas como auxiliar no tratamento. 
- 10-12 Semanas PO: O paciente pode retornar ao uso normal da mão nas AVD’s. Pode ser necessário retardar a preensão de objetos com massa maior, dependendo do conforto do paciente.

A quantidade de força empregada na movimentação e a amplitude que deve ser alcançada, principalmente quando uma força externa aplica a movimentação passiva, depende de informações subjetivas de cada paciente. Na Terapia da Mão, segundo Ferrigno (2007), não se deve estressar muito os tecidos para não causar inflamação importante. O limite do movimento a ser considerado para não criar inflamação excessiva é o respeito à dor, dessa forma o terapeuta define a frequiência e intensidade das manipulações.

O protocolo apresentado e outros de fratura da extremidade distal do rádio não levam em consideração pessoas com resposta fisiológica atípicas. Groth (2004) apresentou um protocolo para reabilitar tendão flexor de dedos suturados onde os exercícios mudam de acordo com etapas alcançadas pelo paciente, não de forma semanal. Portanto, o protocolo que utilizamos como modelo pode ser modificado de acordo com dados obtidos futuramente.

Os dados científicos podem ser obtidos a partir de avaliações clínicas que são norteadoras da prática:

“...um considerável volume de literatura médica, reumatológica e cirúrgica da mão foram concentradas em amplitude de movimento (ADM) dos dedos como primeira fonte de dados no sucesso ou fracasso de muitas de nossas formas de tratamento..." (Cantrell \& Fisher apud HUNTER et al., 2002).

A avaliação dos resultados de processos de reabilitação de pacientes fraturados recebe cada vez mais ênfase nos centros de reabilitação. Segundo Hunter et al. 
(2002), algumas das razões são: o alto custo dos cuidados com a saúde; a variação das práticas entre os centros e indivíduos e a necessidade de avaliações e resultados padronizados. Os dados subjetivos da avaliação são as escalas analógicas de dor e questionários acerca da função dos pacientes e sua satisfação. Os dados objetivos costumam incluir a ADM e a força de preensão. A discussão sobre a determinação da função da mão está ligada à ADM.

Terapeutas necessitam acessar e supervisionar o progresso do paciente identificando possíveis necessidades para ajustamento no procedimento. A ADM é usualmente avaliada com o auxílio de goniômetro. O goniômetro consiste em duas hastes plásticas, unidas em um círculo marcado em graus e presas em um eixo. A goniometria compreende parte da reabilitação, cujos resultados não são facilmente disponíveis e visualizados pelos envolvidos. Segundo Oliveira \& Araújo (2005) nas recomendações da Sociedade Brasileira de Terapeutas da Mão (SBTM), é importante realizar essa avaliação antes de qualquer intervenção para que o tratamento possa ser acompanhado. Segundo Ferrigno (2007), a avaliação também é utilizada como instrumento terapêutico, pois quando o paciente conhece e compreende as técnicas de avaliação pode acompanhar a sua evolução objetivamente.

A confiança da goniometria não foi firmemente estabelecida. Hansson et al. (2009) encontraram erros de avaliação dependendo da posição do antebraço. Pandya et al. (1985) relataram alta confiança quando a goniometria foi realizada por um mesmo terapeuta e baixa confiança quando realizada por diferentes terapeutas. A reabilitação requer métodos precisos, quantitativos e confiáveis para nortear o processo, para oferecer base de dados para pesquisas e para haver uma linguagem comum entre os envolvidos. 
O diálogo entre o cirurgião da mão, terapeuta da mão e paciente é a base para uma reabilitação coerente e eficaz. Para Ferrigno (2007) a proposta da reabilitação "está diretamente vinculada à relação de confiança construída por esta tríade e tem papel fundamental na boa recuperação e na eficácia do tratamento”.

Barbosa et al. (2009) afirmam que nenhuma pesquisa sobre reabilitação de fraturas da extremidade distal do rádio especificam a forma de mensuração de ADM. Os protocolos, tanto na avaliação como na reabilitação, funcionam como um guia para a prática. Oliveira \& Araújo (2005) apresentaram recomendações para prática da avaliação, como o posicionamento do goniômetro e a ADM normalmente atingida de cada articulação:

- Prono/Supinação $\left[0-80^{\circ}\right]$ / [0 -90º (fig.3.1)

- Flexo/Extensão $\left[0-80^{\circ}\right] /\left[0-70^{\circ}\right]$ (fig.3.2)

- Desvio ulnar/Desvio radial $\left[0-30^{\circ}\right] /\left[0-20^{\circ}\right]$ (fig.3.3) 

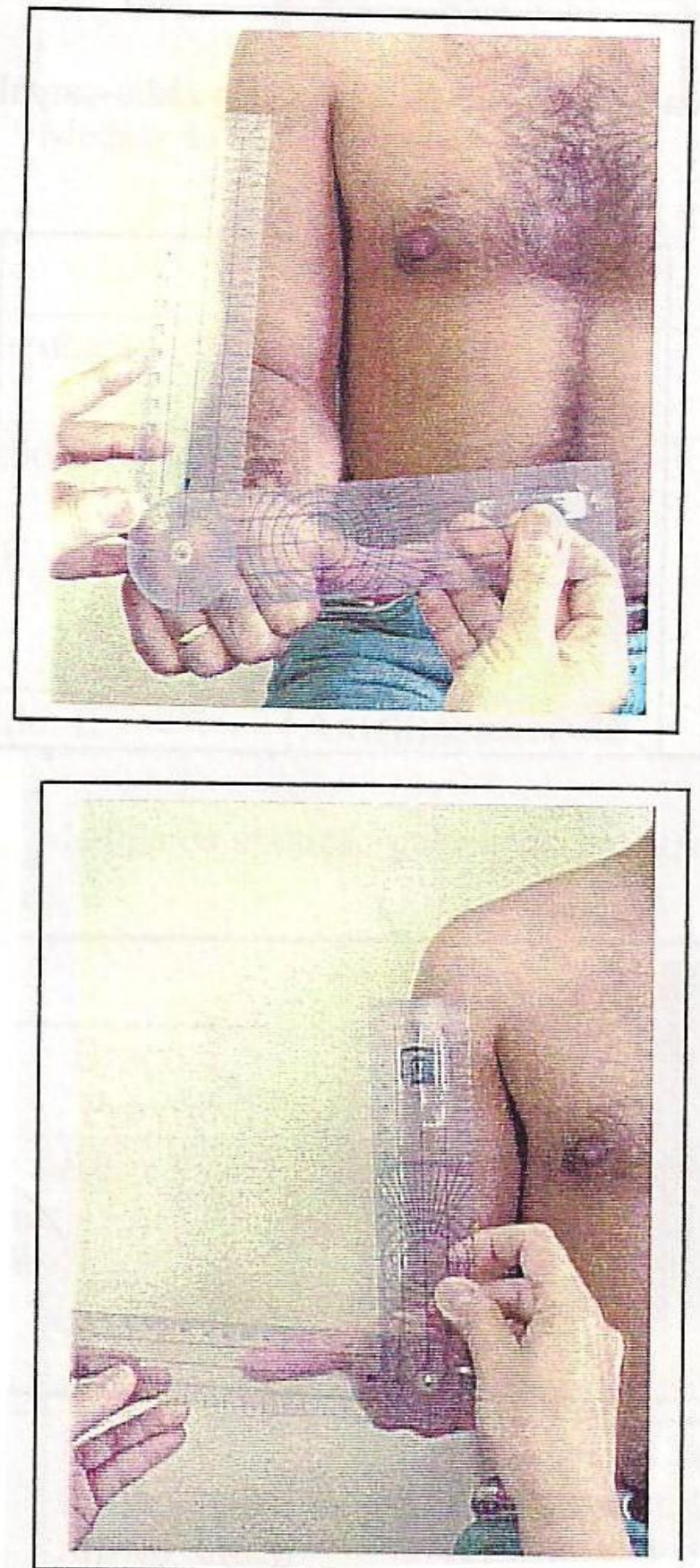

a) Pronação b) Supinação do antebraço

Figura 3.1- Goniometria do antebraço (OLIVEIRA \& ARAÚJO, 2005) 

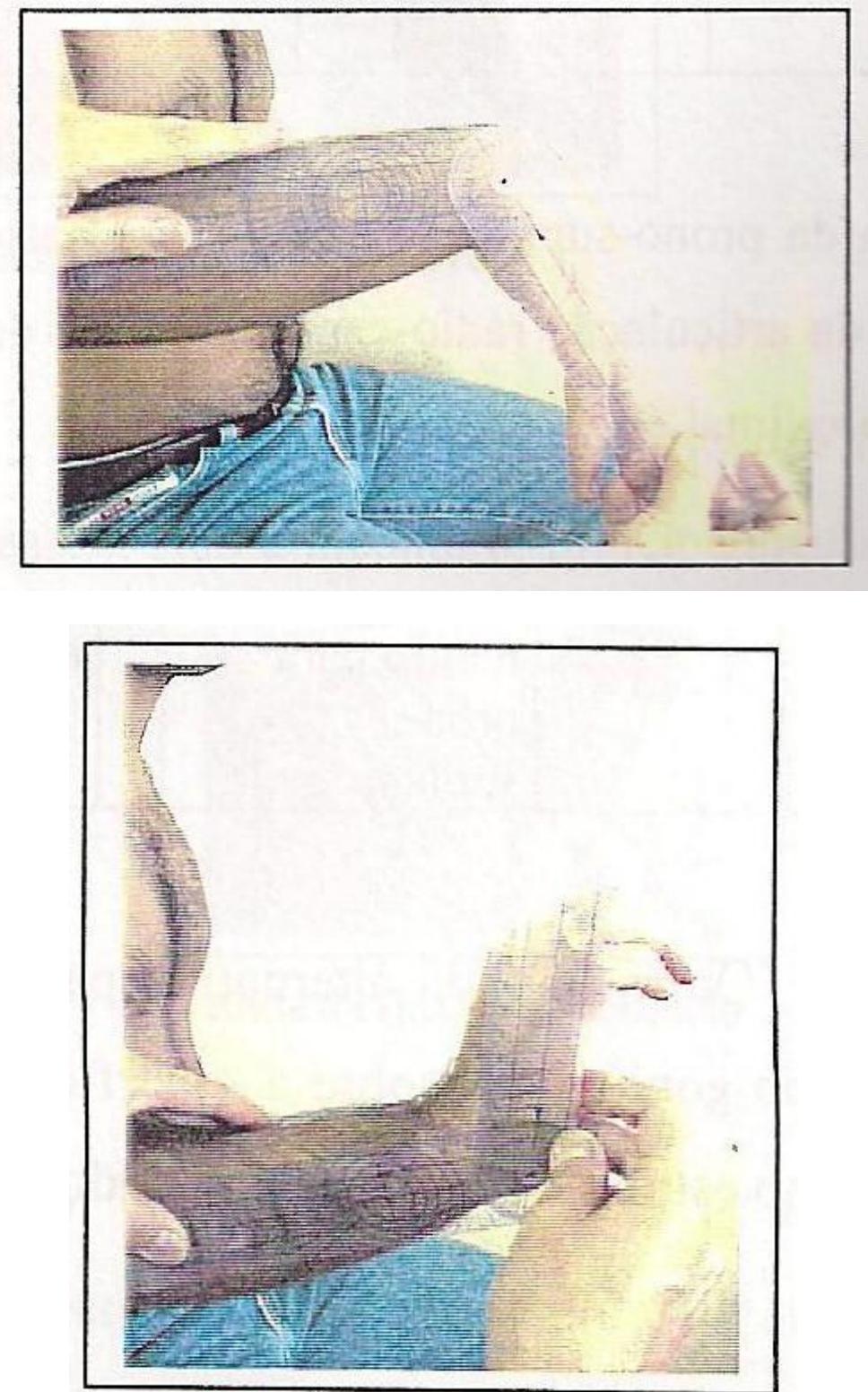

a) Flexão do punho b) Flexão e extesão do punho

Figura 3.2- Goniometria da articulação rádio- cárpica (OLIVEIRA \& ARAÚJO, 2005) 

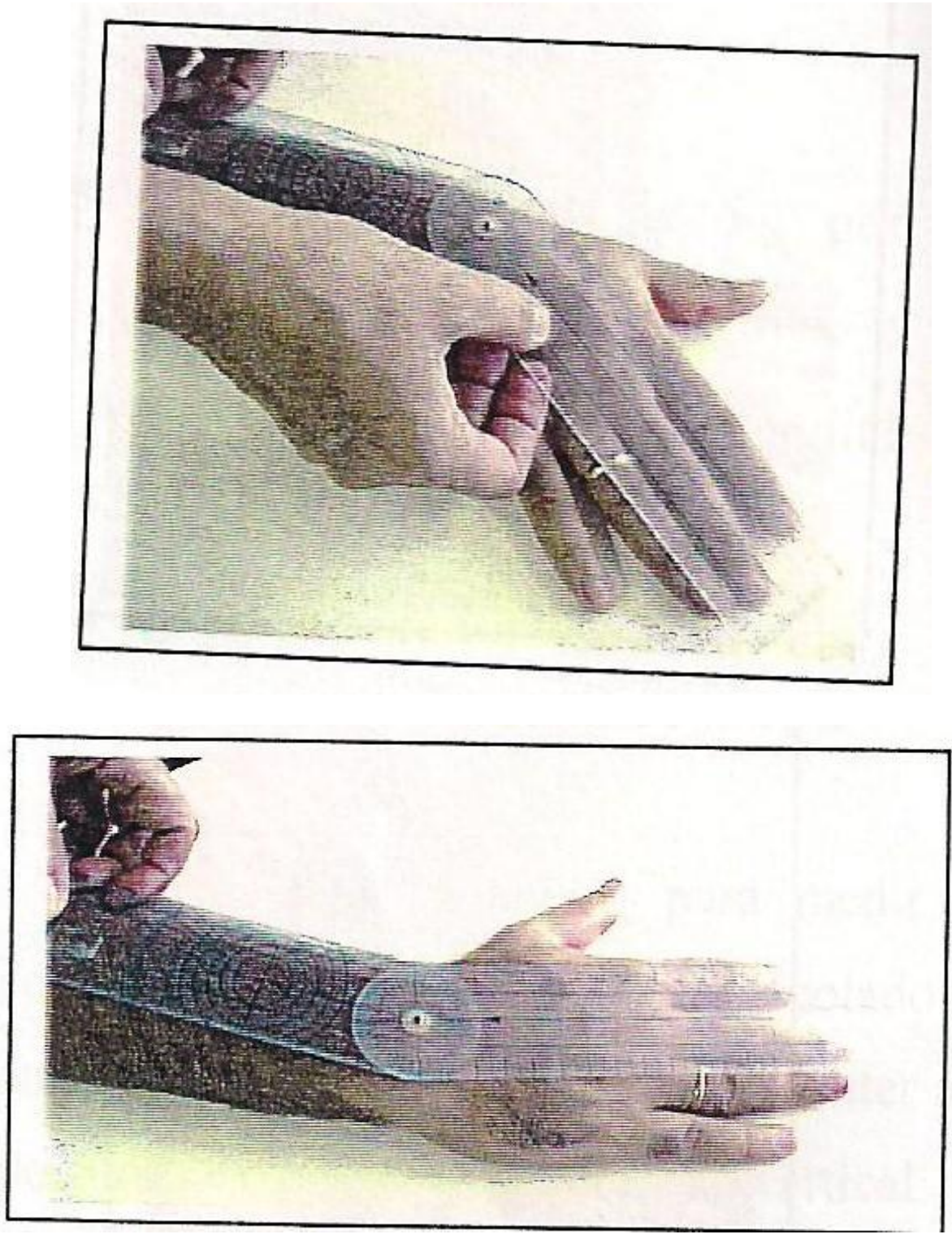

a)Desvio ulnar b) desvio radial

Figura 3.3- Goniometria da articulação rádio- cárpica (OLIVEIRA \& ARAÚJO, 2005).

Oliveira e Araújo (2005) lembram que a goniometria isolada nada significa, mas sim a sua repetição após o tratamento, ou no seu seguimento, para controlar a sua efetividade. Para isto é importante que as medidas sejam feitas sempre na mesma posição, e esta anotada. A posição inicial zero (neutra) recomendada para medir os movimentos de prono-supinação, por convenção, corresponde ao braço colado ao tronco, cotovelo fletido em $90^{\circ}$ e o antebraço posicionado de forma a manter a palma 
da mão voltada para o plano medial do corpo e o polegar para cima na vertical. Fletir o cotovelo do paciente em ângulo reto é essencial, pois com o mesmo estendido seriam acrescentadas as rotações do ombro, com as quais a prono- supinação teria uma amplitude total de $360^{\circ}$. Por outro lado é preciso cuidado com a articulação rádio-cárpica e sua complacência ligamentar que permite maior movimento de prono-supinação quando se segura a mão do paciente (quando se cumprimenta alguém).

A posição neutra para a avaliação radio- cárpica de flexão- extensão e desvio radial- ulnar do punho (fig. 3.2 e 3.3) corresponde ao antebraço pronado, com o eixo alinhado com o terceiro raio digital da mão. Oliveira \& Araújo (2005) alertam para não haver movimentos acessórios como a supinação do antebraço. No punho há diferenças de movimentos. O lado ulnar possui amplitude de movimento maior do que o radial, devido à anatomia e função. Segundo Tang et al. (1999), a posição do terceiro metacarpal é considerada como representativa do movimento do punho e antebraço.

\section{2 - Premissas de projeto mecânico}

O desenvolvimento do hardware, além de se preocupar com o material utilizado na fabricação, deve levar em consideração os protocolos utilizados na reabilitação apresentados e a ergonomia.

\subsection{1 - Ergonomia}

A ergonomia é a ciência que permite planejar locais de trabalho, métodos e produtos que, como seres humanos, podemos utilizar com eficiência, facilidade e segurança. A antropometria - ciência das medidas humanas - é de vital importância 
para a ergonomia. Ela revela as relações entre diferentes dimensões corporais, tais como comprimento do antebraço e estatura. Essas relações podem ser aplicadas no planejamento ou na avaliação do hardware. A aplicação sistemática da antropometria pode minimizar a necessidade das pessoas de se adaptarem a situações desfavoráveis no trabalho, o que, por sua vez, reduz a tensão musculoesquelética do corpo (NORTON \& OLDS, 1966).

O uso de aparelho para reabilitar fratura de membro superior deve ser feito no posicionamento- padrão sentado. Segundo Norton \& Olds (1966), a pessoa deve sentar em um assento horizontal rígido, com a parte superior do corpo ereta, os braços pendendo na vertical e os antebraços mantidos na horizontal. Os pés também devem estar repousando confortavelmente sobre o chão. Os dados disponíveis para o planejamento de produtos são limitados. Ainda são influenciados por vários fatores como idade, sexo, ocupação, condições ambientais, grupos étnicos e a profissão. A TABELA I, dispõe alguns dados antropométricos selecionados para a população britânica que são úteis para a construção do hardware feita por PHEASANT em 1986 (apud NORTON \& OLDS, 1966):

TABELA I- Dados antropométricos de adultos (19 a 65 anos) da população britânica

\begin{tabular}{|l|l|l|}
\hline Dimensão Corporal & Homens & Mulheres \\
\hline & Média $(\mathbf{c m})$ & Média $(\mathbf{c m})$ \\
\hline Estatura & 174,0 & 161,0 \\
\hline Altura sentado & 91,0 & 85,0 \\
\hline Altura do olho, sentado & 79,0 & 74,0 \\
\hline Altura do cotovelo, sentado & 24,5 & 23,5 \\
\hline
\end{tabular}




\begin{tabular}{|l|l|l|}
\hline Comprimento do cotovelo & 47,5 & 43,0 \\
até a ponta do dedo & & \\
\hline
\end{tabular}

Porém, não foram encontrados dados atuais ou nacionais, além das medidas de circunferências do membro superior e comprimento do cotovelo até o punho e do punho até a articulação metacarpofalangeana.

O hardware deve garantir uma distribuição homogênea de pressão deixando a largura do suporte do antebraço, seja ele dorsal ou palmar, se estender até as linhas médias da lateral e medial do membro. Para garantir a estabilidade da mão, a órtese deve apoiar os dois terços distais do comprimento do antebraço (BOSCHEINENMORRIN et al., 2002).

\subsection{2 - Materiais}

O alumínio apresenta- se como uma estrutura leve e economicamente viável. Para as áreas de atrito (buchas), foi utilizado o teflon, por sua relação tribológica (atrito mecânico baixo). Foi utilizado poliacetal para mancais específicos.

O hardware deve ser confortável para o paciente, especialmente pelo fato de muitos apresentarem edema e dor. O conforto significa, além da capacidade de adequação a diferentes tamanhos corpóreos, não irritar ou lesionar a pele do usuário e ser de fácil colocação e retirada.

O hardware necessita ser compacto e ter uma estética agradável para não afastar o usuário que nunca viu ou interagiu com um robô. 


\section{3 - Premissas de integração de sistemas}

Os sistemas robóticos de membro superior existentes podem ser classificados em sistemas passivos (estabilizando o membro corpóreo), ativos (atuadores movendo o membro) e interativos, onde os sistemas são equipados com atuadores com impedância e estratégias de controle permitindo reação nas ações do paciente. Cabe ressaltar que esta classificação de passivo, ativo e interativo é em termos do robô, contrária aos termos do indivíduo. Portanto, movimentos passivos do usuário serão realizados por um sistema robótico ativo e movimentos ativos do usuário são feitos em um sistema robótico passivo ou interativo. Os sistemas podem ser classificados também por graus de liberdade (GdL's) onde o movimento ocorre (TIMMERMANS et al., 2006).

\section{4 - Jogos computacionais}

Programas necessitam ser efetivos para auxiliar pacientes a aperfeiçoar o nível físico, psicológico e de função social, e reduzir o tempo de dependência e de afastamento do trabalho. Para isto, os pacientes são submetidos à avaliação inicial padronizada. Com esses dados, o terapeuta pode proporcionar pequenos desafios nos exercícios do paciente, melhorando as capacidades residuais sem causar fadiga ou frustração. A “Adaptação", segundo Maddison, é uma técnica que o sistema pode utilizar para beneficiar um grupo de usuários com uma ampla gama de habilidades. Para manter a motivação do paciente, atividades de reabilitação podem ser dispostas em um nível apropriado de desafio. O gráfico 3.1 representa a relação capacidadedemanda, quando é proporcional, observa-se uma situação ótima para o desenvolvimento do indivíduo. Entretanto, quando essa relação é desproporcional, no 
sentido da demanda da atividade apresentar-se relativamente mais complexa do que as habilidades, não há o envolvimento do indivíduo, podendo resultar em desinteresse. De forma similar, quando a desproporcionalidade entre capacidade e demanda é no sentido oposto, e as habilidades do indivíduo são relativamente superiores em relação às demandas da atividade ou tarefa, não se observa fluxo, podendo resultar em frustração do indivíduo.

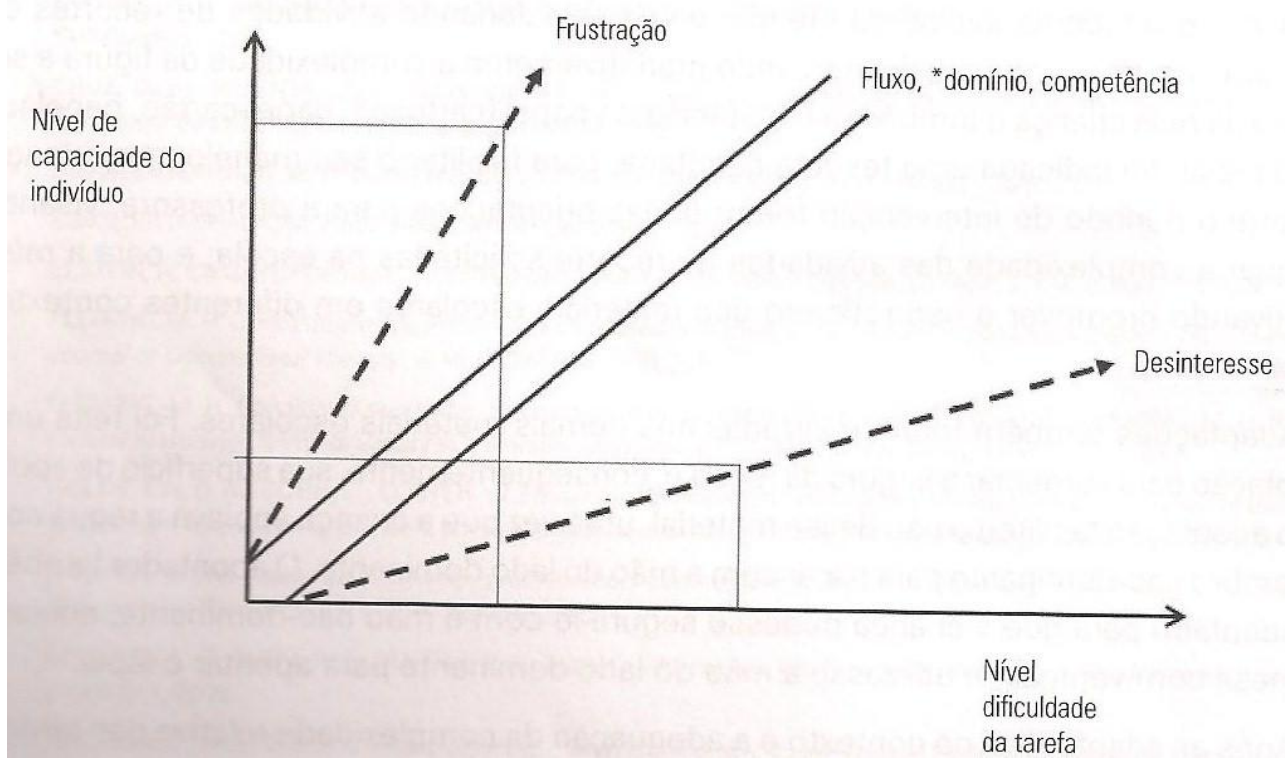

Gráfico 3.1- Processo de fluxo- sensação que o indivíduo experimenta quando funciona de acordo com seu potencial de desempenho (Mancini \& Coelho, 2008)

A importância de administrar a reabilitação, aliada à necessidade de melhorar a motivação do paciente para aderir ao programa de exercícios estabelecidos, são as principais causas para o desenvolvimento de sistemas de reabilitação usando jogos computacionais como "feedback". Isto significa que a percepção do usuário de sua participação ativa em uma atividade concreta (o jogo) ativa uma imagem motora no córtex cerebral capaz de desencadear o envolvimento desejado. Esses sistemas são 
possíveis para aplicações domésticas e tele-reabilitação (KELLER et al., 2010). Em casa os sistemas podem melhorar a autonomia do paciente, a freqüência e a qualidade do tratamento e, simultaneamente, minimizar os custos de longo prazo do cuidado para o sistema nacional de saúde.

O jogo projetado para atender aos requisitos do tratamento, foi planejado em linguagem $C \#$ com $X N A$. A linguagem $C \#$ é uma linguagem objeto- orientada desenvolvida pela Microsoft com arquitetura. Esta é a única linguagem que trabalha com XNA. Este foi desenvolvido também pela Microsoft para simplificar o desenvolvimento de jogos para computador e Xbox 360. Além disso, permite um rápido acesso aos componentes periféricos (teclado, mouse e gamepad Xbox 360), hardware, controle de áudio, área de trabalho e salva as informações em arquivos ou base de dados.

\section{5- Métodos de aplicação do sistema}

Os sujeitos foram informados sobre os objetivos e procedimentos do estudo e, concordando em participar, assinaram um termo de consentimento livre e esclarecido (ANEXO A). O estudo foi aprovado pelo Comitê de Ética em Pesquisa da Universidade Federal de São Carlos.

O sistema foi testado em trinta pessoas saudáveis que, de algum modo, poderão ter contato com o produto futuramente. São elas onze da área da saúde, seis das exatas, oito mulheres pós- menopausa e cinco homens adultos jovens. Os dois últimos grupos representam a população mais acometida pelo tipo de fratura estudada e os dois primeiros são responsáveis pela criação e utilização de novas tecnologias para a saúde. O critério de exclusão foram pessoas com lesões recentes 
(menos de seis meses) em membro superior e quem possui queixas de dor nesta articulação. A falta de dados antropométricos para a circunferência do antebraço torna as pessoas que possuem este membro com medidas maiores que a abertura por onde ele passa no hardware, excluídas da pesquisa. Uma pessoa foi excluída da pesquisa devido este aspecto.

O jogo ocupa o espaço completo da tela do computador, incluindo apenas o placar no centro superior. A tela inicial do jogo foi configurada com a avaliação da ADM máxima de prono-supinação do antebraço do jogador, assim como seu nome, velocidade da bola, quantidade máxima de pontos e uma porcentagem de desafio. Esta última representa a possibilidade do jogo exigir uma movimentação maior do que o potencial inicial do paciente. Foi escolhida uma pequena porcentagem para o teste $(5 \%)$, pois representa um desafio que mantém a capacidade do usuário em jogar, não gerando frustrações ou desinteresses como apresentado no gráfico 3.1. A quantidade máxima de pontos foi programada para sete para não prolongar o tempo correndo o risco de fadiga.

Foram jogadas duas partidas com cada usuário, a primeira com velocidade de oito pixels por segundo e logo após a velocidade entre doze a quinze pixels por segundo. Na primeira configuração, o tempo para a bola atravessar a tela foi de 1', a 3", enquanto na segunda, a bola estava em maior velocidade, levando de 0" 8 ", a 2'. Os graus de movimento gravados a cada segundo no Microsoft Excel foram comparados entre a medida inicial e a máxima atingida durante o jogo.

Durante o jogo é possível perceber pistas sociais. Estas, como expõem Braghirolli et al. (1997), podem ser relatos verbais, observação do comportamento (gestos, postura, expressões faciais, e outros) e indicadores fisiológicos (alteração na 
pressão arterial e na temperatura, tensão muscular, tremor, alteração dos batimentos cardíacos, e respiratórios, sudorese, entre outros) e serão tanto mais próximas dos reais estados emocionais da pessoa quanto maiores forem estes indícios. Durante o uso do sistema foram observadas apenas as expressões faciais dos usuários nesta, por motivo de simplicidade.

Para a avaliação do sistema, também optou-se pela pesquisa quantitativa, que busca uma explicação objetiva dos fatos utilizando descrições estatísticas para saber quanto de satisfação o produto está alcançando. Ao final do teste, além dos dados obtidos para futuras análises sobre o sistema, será respondido um questionário (ANEXO B) com catorze questões e espaços para críticas e sugestões, visando melhorias futuras baseado em diversos conhecimentos. O questionário primeiramente caracteriza o usuário, situando-o em qual grupo pertence e se teve alguma vivência como paciente de reabilitação física. Depois preocupa-se com a qualidade do aparelho, indagando sobre o conforto, o design, o sentimento de segurança para a utilização, a facilidade de limpeza, de transporte, de compreensão da utilização, a confiabilidade do sistema e a motivação transmitida pelo jogo. Por último propõe a situação hipotética de ter que reabilitar o punho e questiona se, e de que forma, utilizaria o sistema. 


\section{Capítulo 4}

\section{4 - Projeto desenvolvido}

O sistema foi desenvolvido integrando o projeto mecânico, elétrico e de software (jogo). A seguir será apresentado cada um detalhadamente e mostrado os resultados da aplicação.

\section{1 - O projeto mecânico}

O hardware desenvolvido é classificado em três graus de liberdade, com movimentos de flexo- extensão e desvio ulnar- radial da articulação rádio- cárpica e prono- supinação do antebraço feitos deslocando a manopla (fig.4.1).

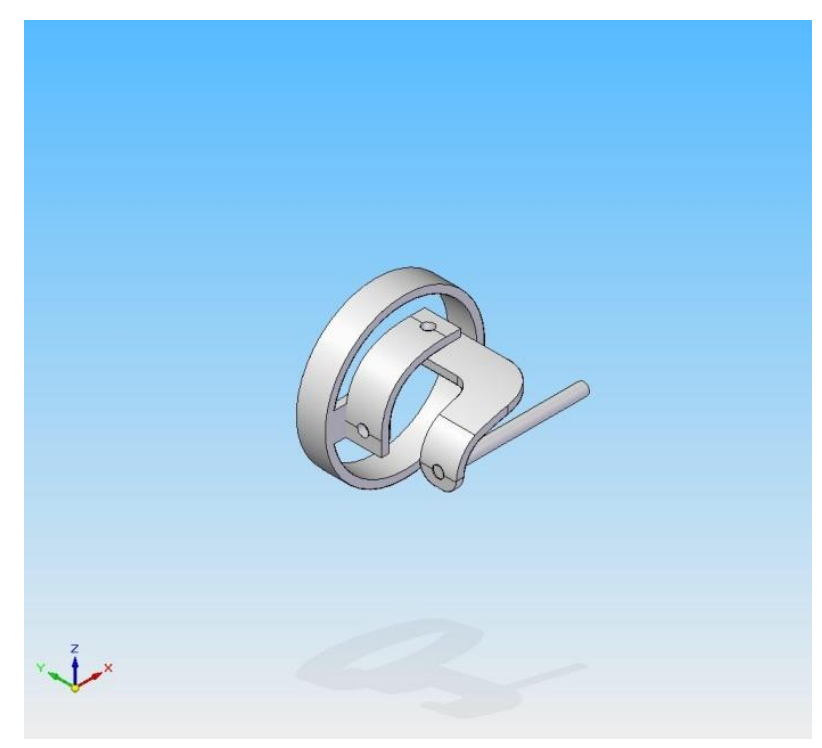

Figura 4.1- Conceito do mecanismo da manopla

O apoio do antebraço foi projetado com comprimento suficiente para qualquer tamanho de membro, (fig.4.2). Para proporcionar maior alavanca, o antebraço pode ser preso ao aparelho com auxílio de velcros. Este apoio deve ser 
macio, confeccionado com espuma e capa de tecido. O punho não pode ter suporte para que o movimento seja liberado. Para mover a manopla, a preensão da mão pode ser feita em um modelo anatômico, de espuma, e fixado com velcro que auxilia a estabilizar os ossos metacárpicos da mão à manopla, e possibilita a preensão em casos de usuários com déficit de movimentos de dedos.

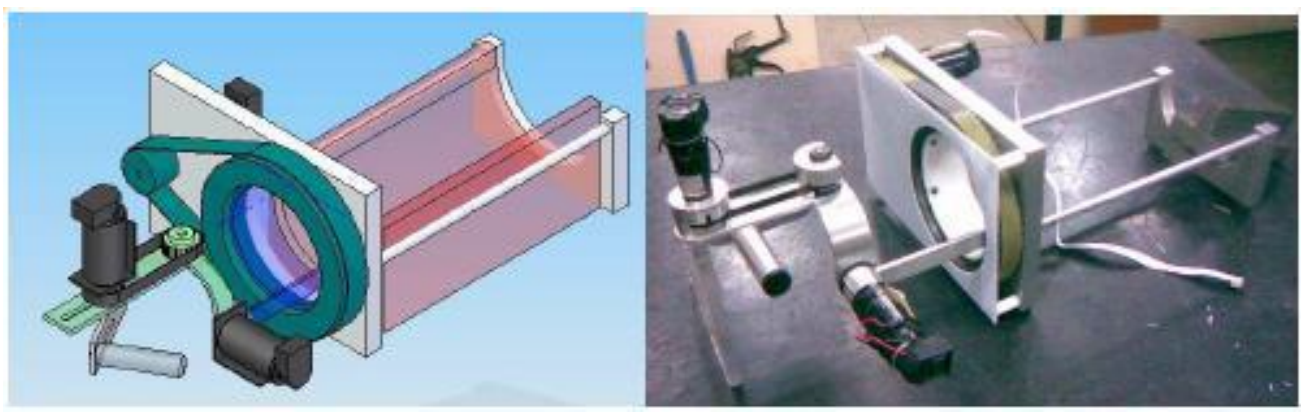

a) Desenho do protótipo. b) Início da construção do protótipo.

Figura 4.2- Projeto do protótipo

Para apoiar o aparelho de acordo com a ergonomia, o cotovelo do usuário sentado deve estar fletido $90^{\circ}$ próximo ao corpo. Uma mesa de pequeno porte, com regulagem de altura para apoiar o aparelho, foi planejada para garantir esta posição.

Alguns requisitos são importantes para um dispositivo que opera próximo (contato direto) com o usuário. São eles:

- Robustez, disponibilidade e confiabilidade;

- Simplicidade de uso e interface amigável;

- Segurança - proteção do usuário;

- Portabilidade;

- Simplicidade de operação e de manutenção. 


\section{2 - O projeto eletrônico}

O hardware foi projetado com três motores elétricos Maxon RE40 que apresenta tamanho aceitável e três EPOS para realizar a aquisição dos dados. O Motor Maxon DC é uma máquina para transformar a energia elétrica em mecânica. Este motor com encoders e um Drive de controle - EPOS (Easy-to-use Positioning) são responsáveis por medir os ângulos do punho, e por comunicar com o jogo por uma conexão RS232. Todos os dados coletados podem ser gravados e processados no mesmo computador onde o jogo roda.

O framework que integra o hardware aos jogos, provê uma estrutura básica para criação deste último, utilizando a EPOS com dispositivo de entrada e saída de comandos. A ideia é proporcionar ao desenvolvedor de jogos uma base para a construção da interação com a EPOS, de maneira que é possível ajustar o uso do framework de acordo com as necessidades do projeto a ser desenvolvido.

O framework desenvolvido até o momento é modular, a fim de ser facilmente utilizado, alterado e até mesmo modificado. A sua arquitetura global é apresentado na figura 4.3. É importante destacar que este framework foi desenvolvido para ser utilizado para jogos criados com C\# e XNA (Lobão et al.. 2009). 


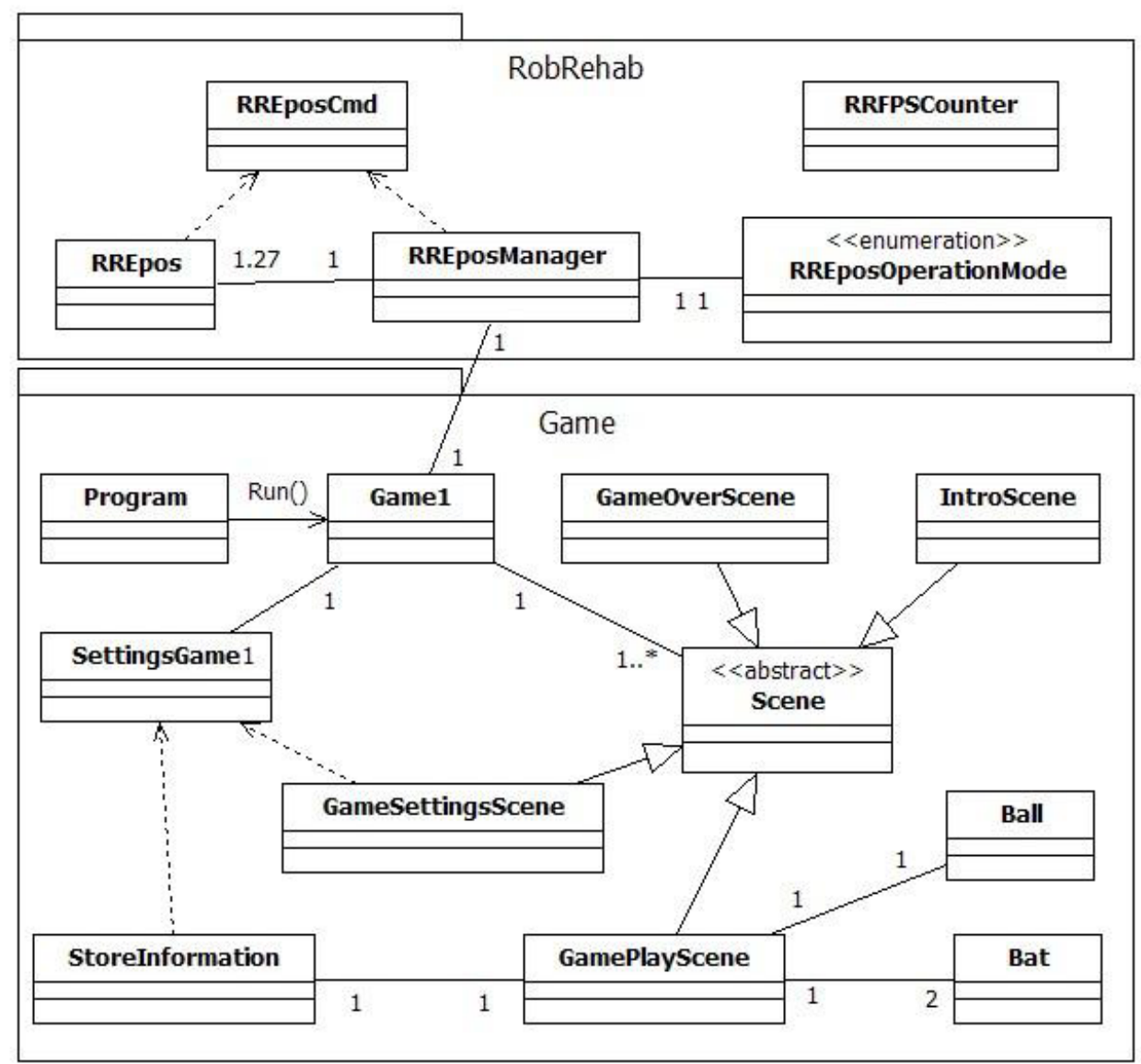

Figura 4.3- Diagrama do jogo

- RREposCmd: define funções a biblioteca EposCmd.dll para ser utilizado com a linguagem $C \#$.

- RREpos: define o objeto EPOS afim de utilizar suas entradas e saídas digitais, assim como a entrada analógica e o encoder, conforme operações definidas.

- RREposManager: gerência até 128 EPOS ligadas em rede CAN entre elas, conforme o hardware desenvolvido para aquisição ou envio de dados para controle. 
- RREposOperationMode: Define os métodos de operação da EPOS como: modo de posição, velocidade, corrente...

- RRFPSCounter: Componente de jogo para saber quantos frames por segundo o jogo está sendo executado.

O amplificador digital EPOS pode fazer controle de corrente, posição ou velocidade do motor com valores pré- definidos através do serial ou interfaces CANopen. Uma classificação de variáveis, incluindo posição, velocidade e corrente do motor pode ser feita usando essas interfaces. $\mathrm{O}$ aparelho pode mensurar até oito dados análogos.

Em um equipamento como este, onde há o contato direto com o ser humano, há o risco de lesão se os movimentos realizados pelo aparelho forem maiores que a ADM biomecânica da articulação. A velocidade e a força aplicada pelo aparelho no movimento passivo podem ser excessivas. Para que isto não ocorra, foram planejados sistemas de segurança em paralelo, com atuação elétrica ou mecânica e restrição da potência do motor. Desta maneira há controle do movimento, força e velocidade, prevenindo lesões.

\section{3 - O projeto de software/jogo}

O jogo projetado foi o "Pong" por ser de fácil compreensão das regras e objetivo. O usuário utiliza os movimentos do punho no hardware para mover uma barra na lateral esquerda da tela tentando acertar a bola que, se encostada pela barra, corre para o lado oposto, onde o adversário tentará rebater utilizando o teclado do computador como controle, o objetivo é ganhar pontos para vencer o jogo. Isso acontece quando o adversário não consegue rebater a bola. 
Uma área inicial com nome do usuário, velocidade da bola, número máximo de pontos, amplitude de movimento e porcentagem de desafio durante o jogo forçando uma amplitude maior de movimento é planejada para personalizar a dificuldade do jogo.

A imagem de fundo fixa e o áudio foram planejados para não atraírem muita atenção e ao mesmo tempo serem agradáveis, estimulando a prática do jogo. A imagem da bola e da barra necessitam de destaque com cores fortes para serem facilmente visualizados (fig.4.4). O volume do áudio pode ser controlado pelo ajuste do computador.

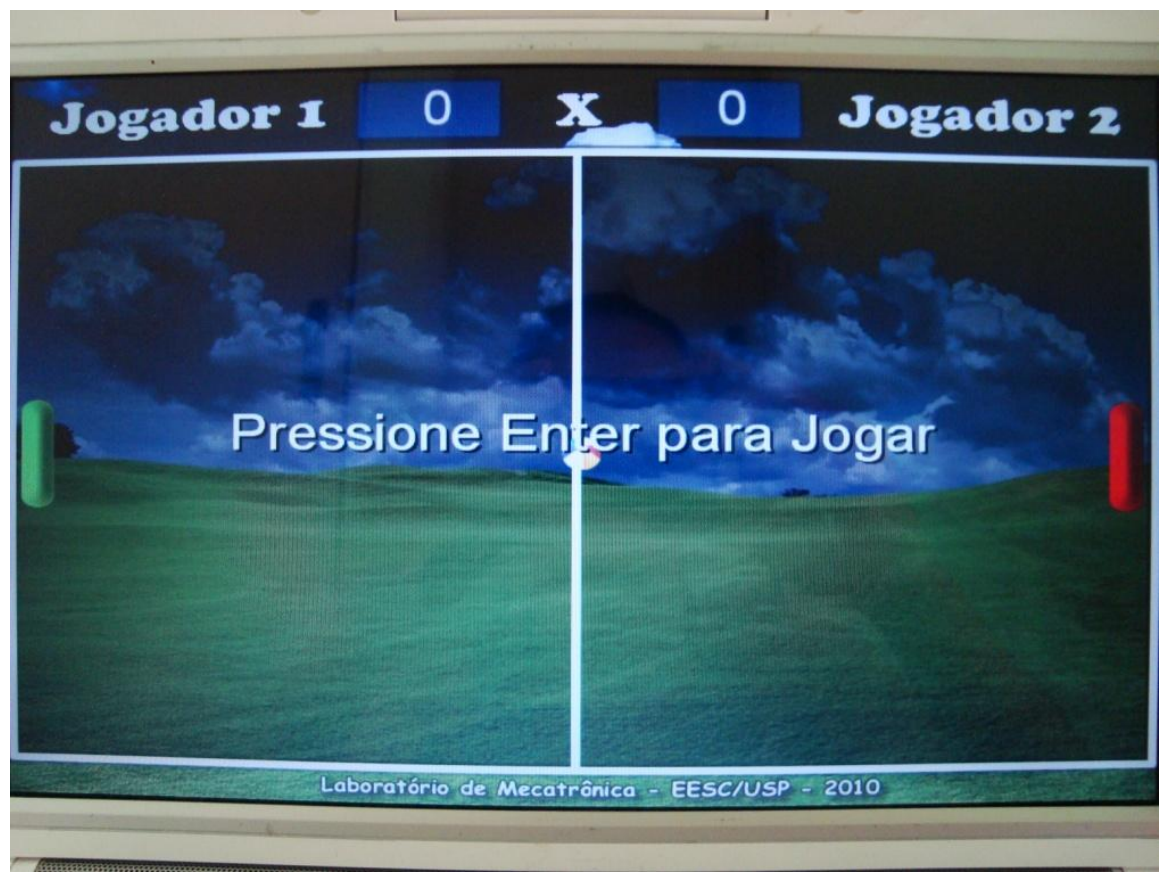

Figura 4.4- Cenário do jogo 


\section{Capítulo 5}

\section{5 - Resultados e Discussões}

Os resultados juntamente com as discussões são apresentados na seguinte ordem: o protótipo, o sistema, as respostas do questionário, as amplitudes de movimento e as expressões faciais.

\section{1 - Protótipo}

O protótipo (fig.15) desenvolvido possui três GdL's, porém, por motivo de simplicidade, apenas um recebeu um motor elétrico e foi utilizado para teste; o de prono-supinação de antebraço. Os outros dois GdL's foram presos com travas mecânicas.

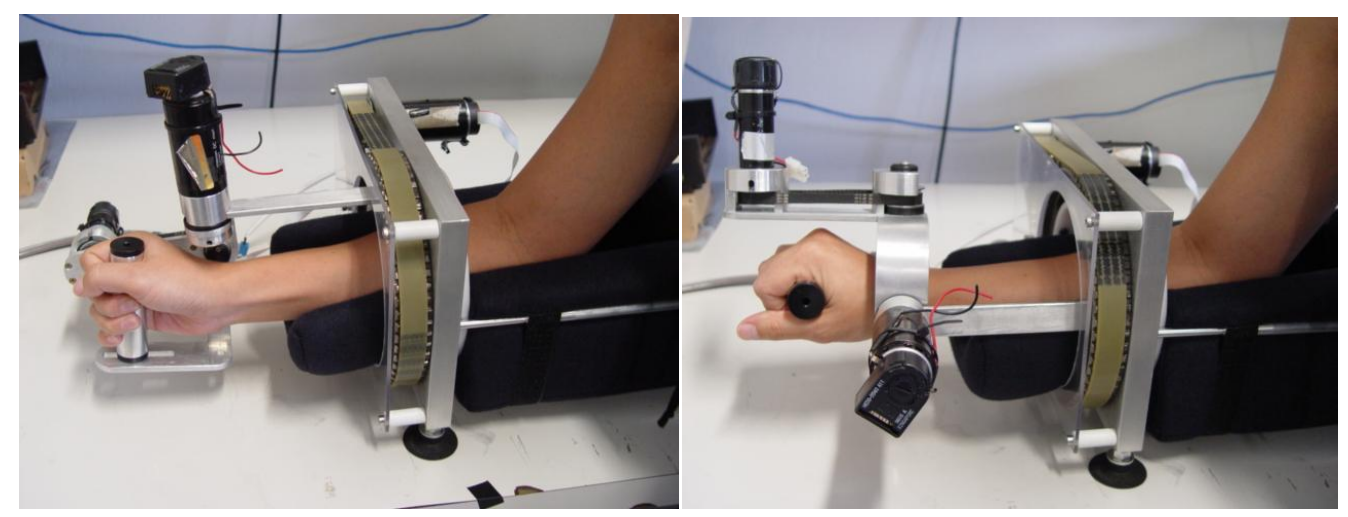

a) Protótipo com antebraço na posição neutra b) Na posição pronada

Figura 5.1- Protótipo

A manopla foi coberta, posteriormente com um guidão de espuma anatômico. Para a mão ficar fixa, mesmo sem haver flexão de dedo, um velcro foi colocado cruzando os ossos metacárpicos (fig.5.2). 
O apoio de antebraço estende-se por todo o seu comprimento, deixando apenas o punho livre e fazendo alavanca para os movimentos da mão. Um velcro foi colocado para auxiliar este apoio.

Considerando a ergonomia, o hardware fica apoiado sobre uma mesa construída com regulagem de altura (fig.5.2).

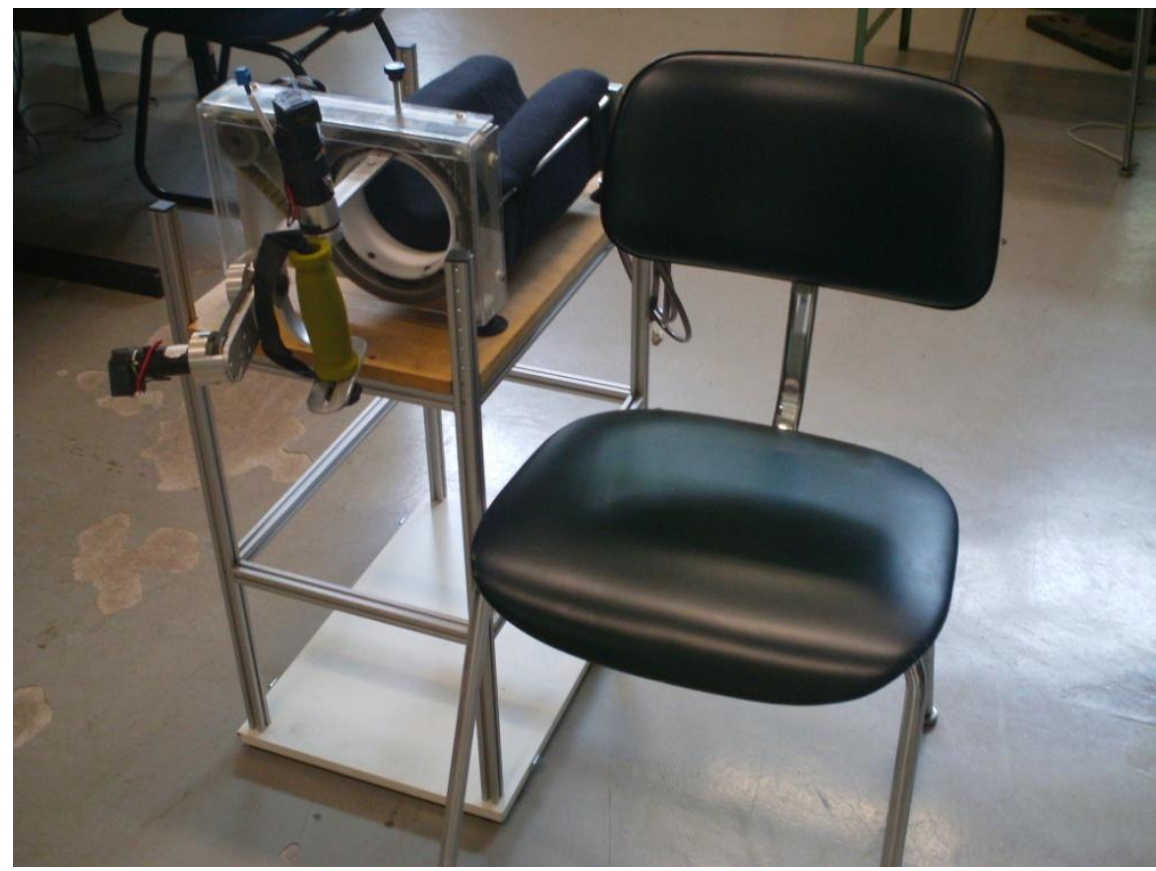

Figura 5.2- Hardware apoiado sobre mesa com opção de regulagem de altura

\section{2 - Sistema}

Apenas a fase inicial de reabilitação foi alcançada utilizando uma EPOS, com o usuário fazendo a movimentação ativa. O sistema é classificado como passivo. Porém o sistema é capaz de realizar as outras fases de reabilitação, necessitando de controle de impedância.

O jogo "Pong" apresenta uma paisagem de natureza (fig.5.3). A tela inicial apresenta a avaliação e configuração do jogo. A barra verde é controlada por movimentos de prono-supinação no hardware e a barra vermelha pelo teclado do 
computador. A bola colorida é destacada com borda preta. O placar situa-se na parte de cima da tela.
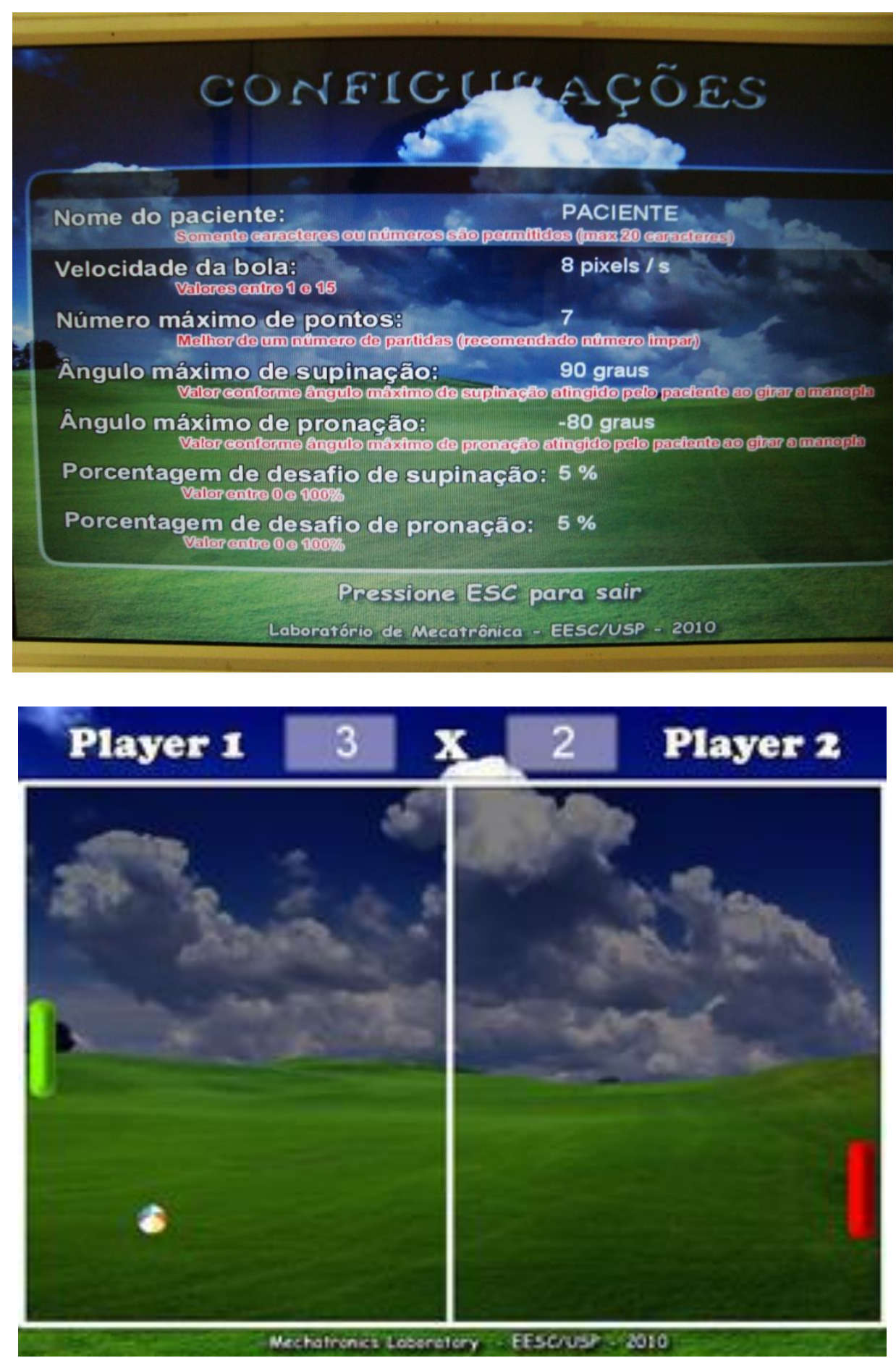

a) Tela inicial b) Jogo em andamento

Figura 5.3- Jogo "Pong" 
Quando um novo jogo é iniciado, é criado então um arquivo com o nome do jogador, data e hora no qual é armazenada a configuração inicial da partida. No final este arquivo irá recolher informações da partida a cada ciclo de tempo (60 frames por segundo $-60 \mathrm{~Hz}$ ) armazenando o ângulo que o jogador alcança naquele momento, pontuação do jogo, e demais informações que são importantes para avaliação do paciente.

O sistema é móvel baixando o programa em notebook podendo ser levado para domicílio (fig.5.4).

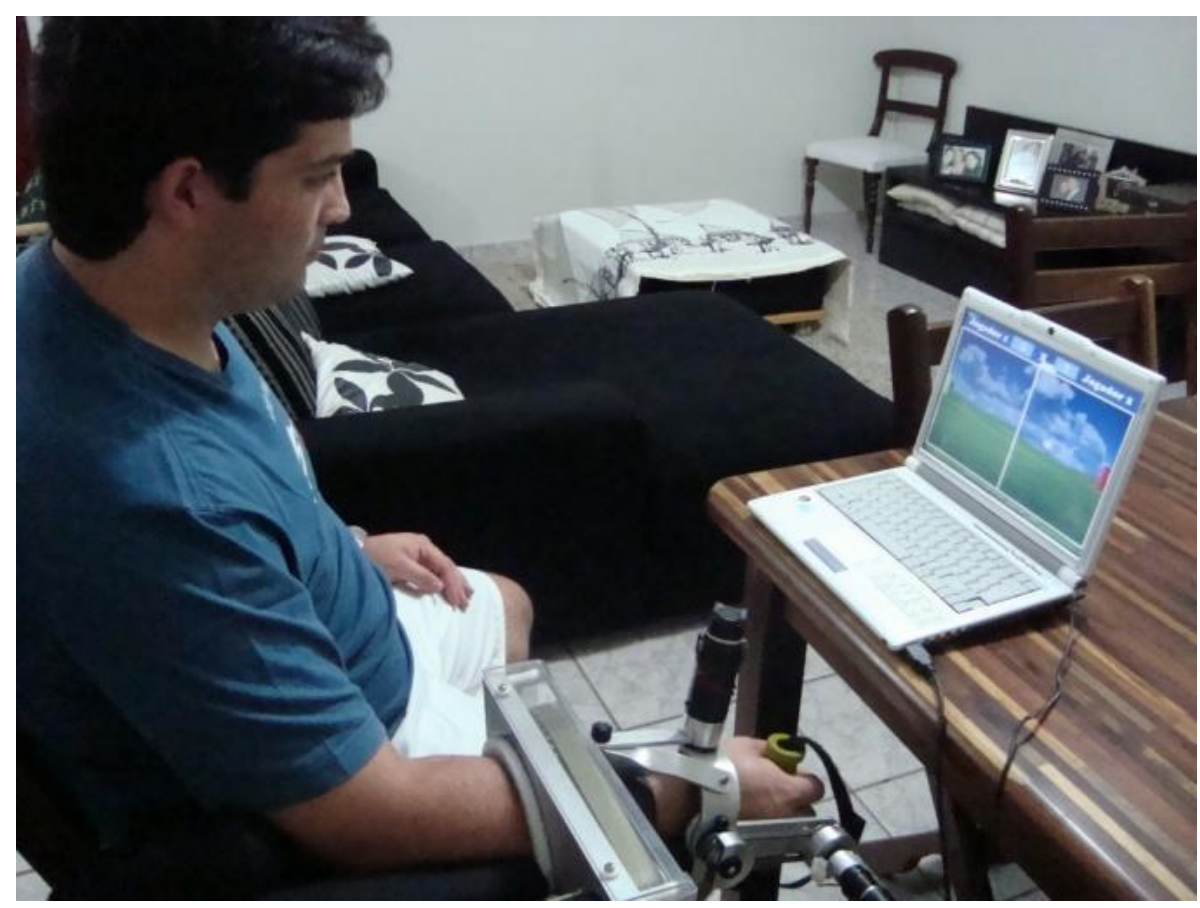

Figura 5.4- Uso do sistema em domicílio

\section{3 - Questionário}

As respostas dos questionários realizados em pessoas saudáveis, da área da saúde, das exatas, mulheres pós- menopausa e homens adulto jovens foram organizadas na TABELA II (ANEXO C). 
Os dados são representados em cores, de acordo com o sugerido em Soares e Carvalho (2009) como um meio visual para acompanhar os resultados. O verde significa obtenção de sucesso no item questionado, azul indica que o item está dentro das características recomendadas, o amarelo indica que o parâmetro está fora do planejado e o vermelho significa que o item apresenta- se pior que o objetivo. Os dois últimos requerem um plano de ação para melhorias. Apenas com os resultados azuis e verdes, significando um protótipo de acordo com as expectativas e requisitos, é possível aplicar em pacientes em reabilitação.

A análise dos questionários aponta para a total satisfação com o sentimento de segurança durante o uso do sistema, sua utilidade e o uso do jogo na reabilitação, com respostas de satisfação ou muita satisfação. Três pessoas sugeriram diversificar os jogos para haver mais opções para o usuário.

Apenas uma pessoa teve pouca satisfação com a facilidade de entendimento do uso. Também uma pessoa respondeu que faria pouco uso do aparelho caso precisasse de reabilitação.

A facilidade de limpeza do hardware e a confiança do sistema foram desaprovadas por três pessoas com pouca satisfação. A sugestão quanto à limpeza foi envolver a espuma com tecido impermeável e lavável. Quanto à confiança do sistema, a indicação foi fixar melhor o terceiro metacarpo à manopla, para que não haja movimentos de dedos aumentando a mensuração da ADM do punho. Apontaram para a necessidade em deixar o movimento do punho sem resistência para movimentos ativos iniciais. 
Quanto a mobilidade do equipamento, quatro pessoas ficaram pouco satisfeitas. Idealizaram fazer uma maleta para guardar o sistema.

Ao menos uma pessoa expressou insatisfação total no aspecto ergonômico, conforto e estética do hardware. A ergonomia foi a mais criticada, com três pessoas insatisfeitas. Modificar a abertura por onde a mão atravessa, para que comporte todos os tamanhos que possam ser encontrados, aumentar o espaço entre a parte dorsal da mão e as ferragens foram as sugestões para esse aspecto e para melhorar o conforto. A estética pode ser melhorada com motores menores.

Os trabalhos futuros pretendem melhorar o hardware para minimizar tais insatisfações, utilizando algumas sugestões adquiridas pelo questionário.

\section{4 - Amplitude de Movimento}

A tabela mostra a amplitude de movimento inicial (avaliação antes do jogo) e a máxima obtida durante o jogo para cada usuário.

Tabela III: ADM de prono- supinação de antebraço inicial e ADM máxima durante o jogo

\begin{tabular}{|c|c|c|c|c|}
\hline Usuário & $\begin{array}{l}\text { Pronação } \\
\text { inicial }\end{array}$ & $\begin{array}{l}\text { Pronação } \\
\text { máxima }\end{array}$ & $\begin{array}{l}\text { Supinação } \\
\text { inicial }\end{array}$ & $\begin{array}{l}\text { Supinação } \\
\text { máxima }\end{array}$ \\
\hline 1-Saúde & 64,9 & 88,4 & 99,1 & 99,8 \\
\hline 2 - Exatas & 53,5 & 49,3 & 50,9 & 64,1 \\
\hline 3 - Mulher & 85,7 & 85,7 & 80,1 & 60,3 \\
\hline
\end{tabular}




\begin{tabular}{|c|c|c|c|c|}
\hline 4 - Exatas & 60,4 & 60,4 & 59,2 & 82,7 \\
\hline 5-Mulher & 52,0 & 32,3 & 96,6 & 92,1 \\
\hline 6 - Exatas & 73,6 & 55,9 & 67,8 & 59,6 \\
\hline 7 - Homem & 70,0 & 23,8 & 44,3 & 43,9 \\
\hline 8 -Saúde & 107,3 & 74,4 & 69,0 & 63,6 \\
\hline 9-Saúde & 73,9 & 53,8 & 70,4 & 92,3 \\
\hline $\begin{array}{l}10- \\
\text { Homem }\end{array}$ & 66,8 & 65,8 & 53,3 & 53,7 \\
\hline 11 - Saúde & 76,6 & 84,8 & 56,9 & 61,1 \\
\hline 12 - Saúde & 57,5 & 58,6 & 63,4 & 64,9 \\
\hline $\begin{array}{l}13- \\
\text { Homem }\end{array}$ & 102,4 & 46,8 & 61,6 & 69,5 \\
\hline $\begin{array}{l}14- \\
\text { Mulher }\end{array}$ & 95,1 & 0 & 56,7 & 77,2 \\
\hline 15 - Exatas & 63,3 & 60,4 & 57,8 & 58,9 \\
\hline $\begin{array}{l}16- \\
\text { Mulher }\end{array}$ & 93,2 & 88,2 & 76,9 & 67,3 \\
\hline $\begin{array}{l}17- \\
\text { Homem }\end{array}$ & 42,9 & 42,6 & 67,0 & 38,2 \\
\hline 18 - Saúde & 65,1 & 58,9 & 63,3 & 60,6 \\
\hline 19 - Saúde & 65,9 & 59,4 & 65,5 & 68,0 \\
\hline 20 - Exatas & 81,6 & 62,5 & 69,0 & 63,6 \\
\hline 21 - Saúde & 54,3 & 34,2 & 59,5 & 52,8 \\
\hline
\end{tabular}




\begin{tabular}{|l|l|l|l|l|}
\hline $\begin{array}{l}22- \\
\text { Mulher }\end{array}$ & 75,0 & 40,9 & 46,6 & 24,8 \\
\hline $23-$ & 63,4 & 56,9 & 85,6 & 48,4 \\
Mulher & & & & \\
\hline $24-$ Exatas & 77,7 & 77,7 & 89,0 & 74,5 \\
\hline $25-$ Saúde & 54,0 & 50,0 & 50,3 & 43,2 \\
\hline $26-$ Saúde & 86,4 & 80,5 & 52,0 & 57,0 \\
\hline $27-$ & 81,3 & 79,6 & 65,0 & 64,1 \\
Homem & & & & \\
\hline $28-$ & 41,1 & 41,1 & 72,3 & 55,1 \\
Mulher & & & & \\
\hline $29-$ & 82,9 & 86,5 & 23,3 & \\
\hline Mulher & & & & \\
\hline
\end{tabular}

Os realces de cor dos números mostram quando a ADM durante o jogo foi maior do que a ADM inicial. Das 29 pessoas testadas, $13(44,8 \%)$ apresentaram ADM maior. Dentre estes, $4(30,8 \%)$ tiveram resultados maiores ambos em pronação e supinação e 9 (69\%) apenas em supinação. Nenhum usuário aumentou apenas a pronação.

A média de $\mathrm{ADM}$ foi de $71.3^{\circ}$, sendo que a maior $\mathrm{ADM}$ de pronação foi $107,3^{\circ}$ feita na medida inicial em um profissional da saúde homem e $88,4^{\circ}$ durante o jogo por outro profissional da saúde homem. A maior supinação inicial foi de 99,1 também por profissional da saúde homem e este mesmo fez a maior ADM de supinação durante o jogo: 99,8. As menores ADM's foram feitas por mulheres pós 
menopausa. Pronação inicial: $41,1^{\circ}$; durante o jogo $0^{\circ}$, supinação inicial: $23,3^{\circ}$ e durante o jogo: $24,8^{\circ}$. A amplitude de movimento não foi máxima para todos os jogadores. Isso pode ser explicado pelo fato da bola do jogo "Pong" ter direções aleatórias, não havendo controle para que o usuário necessite atingir a ADM máxima em todas as partidas.

A média de tempo jogado por partida foi de 36,4 segundos, onde a partida mais longa durou 84 segundos com um usuário homem jovem e a mais curta, 16 segundos com uma mulher pós- menopausa.

Ambos, amplitude de movimento e tempo de duração de partida, foram menores em mulheres pós- menopausa. Um dos motivos a ser considerado é a falta de controle de impedância que deixou os movimentos com resistência, dificultando a atividade para quem tem menos massa muscular.

Os usuários não tiveram treino para o jogo. Os resultados são do primeiro contato do jogador com o sistema.

Para modificar o modelo de prática baseada em eminência é importante que a conduta terapêutica seja bem documentada e atestada cientificamente (BARBOSA et al., 2009).

O gráfico 5.1 da ADM de um participante durante o jogo pode ser mostrado em ângulos por segundo, marcando o momento em que um participante marca o ponto. Pode- se observar o movimento de pronação e supinação. Há um momento em que há um pico com a máxima supinação, porém, neste caso, esta amplitude não se repete durante todo o jogo. 


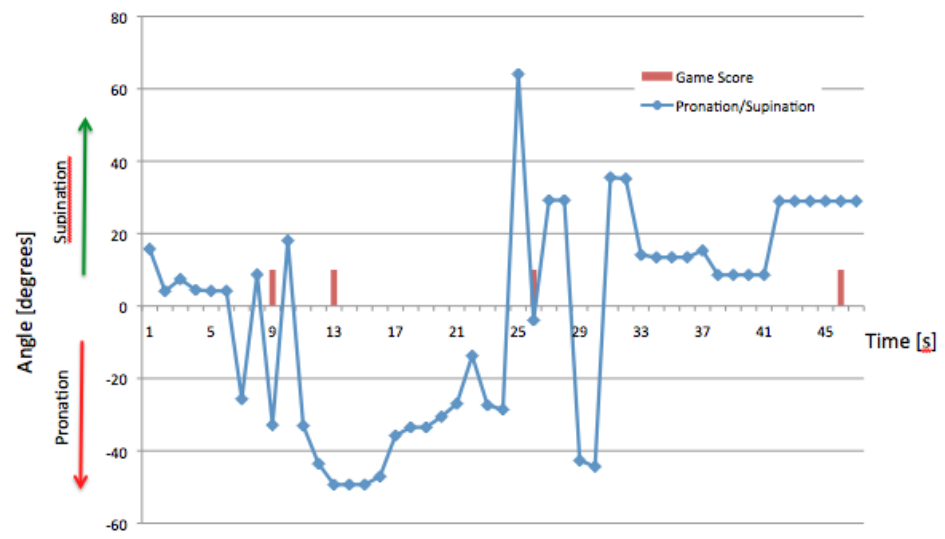

Gráfico 5.1- ADM por segundo durante o jogo

\section{5 - Expressões faciais}

Durante o teste com jogos, todos os usuários expressaram risos e sorrisos indicando boas emoções. Como dito anteriormente as emoções atendem à preparação motora para a reação e podem potencializar a reabilitação. 


\section{Capítulo 6}

\section{6 - Conclusões e trabalhos futuros}

O projeto atendeu a grande parte das expectativas. O protótipo permite os movimentos necessários para a reabilitação de uma maneira agradável, como foi observado nas expressões faciais dos usuários. O sistema armazena os dados dos movimentos estimulados pelo jogo, que se apresentaram maior durante a atividade do que na medida inicial. Este fato pode ter ocorrido devido ao estímulo do jogo, porém a melhora da fixação da mão à manopla (não permitindo nenhum movimento do hardware apenas pelos dedos) pode trazer maior fidedignidade aos resultados.

O estudo mostrou que o jogo constitui um fator importante para o estímulo da reabilitação, porém, se houver jogos que permitam um maior controle dos movimentos requisitados durante a atividade, poderão ser mais úteis para a terapia.

Alguns objetivos do sistema não foram alcançados por falta de recursos. Isto deve ser suprido com apoios financeiros. Com a implementação do controle de impedância, o hardware ficará livre para quem tem pouca força muscular (principalmente mulheres pós menopausa) e quem precisa fazer a movimentação ativa na fase inicial, ainda oferecerá resistência para fazer o fortalecimento gradual. Implementar a visualização de dados com diversos tipos de gráficos (comparando dados de sessões passadas, comparando apenas um movimento, e outros) e jogos via internet foram postergados para trabalhos futuros. 
A análise dos dados obtidos e das respostas do questionário é importante para planejar e realizar melhorias no sistema antes de ser testado em pacientes. A adaptação dos aparelhos a todos os pacientes é primordial em sua construção. Estudo antropométrico de circunferência da mão deve ser realizado para a melhoria do hardware. A ergonomia é essencial para a fidedignidade das avaliações e das reabilitações.

As tecnologias existentes podem auxiliar na reabilitação de diversas lesões. Porém, hardware, jogos e sistemas devem atender às necessidades específicas de traumas ou patologias e às expectativas de usuários, precisando ser elaborados, pesquisados e melhorados em parcerias entre profissionais da saúde, das exatas e usuários.

A partir de protocolos existentes que baseiam-se em mudanças fisiológicas gerais e de dados obtidos de pesquisas durante processos de reabilitação de pacientes, pretende-se elaborar e testar um protocolo para reabilitação de fratura da extremidade distal do rádio. Os conhecimentos de especialistas e pesquisas de base de dados poderão inferir regras que mudam os exercícios de acordo com as tarefas alcançadas. Deste modo, a reabilitação poderá ser individualizada e coerente.

Por fim, é importante citar que o sistema não substitui o contato físico com o Terapeuta Ocupacional e nem supre todas as demandas da reabilitação. Trata- se de um complemento no tratamento e uma forma de adquirir dados científicos para nortear a prática. 


\section{Referências:}

Associação de Terapeutas Ocupacionais do Estado de São Paulo (ATOESP).

Disponível em:

$<$ http://www.atoesp.org.br/index.php?option=com_content\&view=article\&id=77:def

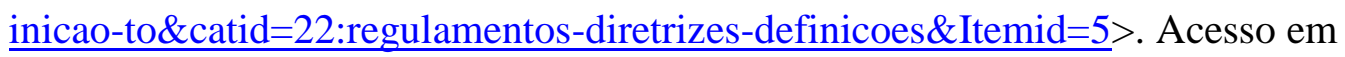
setembro de 2010 .

BARBOSA, P. S. H.; TEIXEIRA-SALMELA, L. F.; CRUZ, R. B. Rehabilitation of distal radius fractures. Acta ortop. bras., São Paulo, v.17, n. 3, p.182-186, 2009.

BESNIER, B. A Distinção entre Praxix e Poiêsis em Aristóteles. Ecole Normale Supérieure de Fontenay-St-Cloud, Analytica, vol 1, n. 3, p.127-163, 1996.

BOSCHEINEN-MORRIN, J.; DAVEY, V.; CONOLLY, W. B. A Mão: Bases da Terapia. 1. ed. Manole, 2002. 300p.

BRACHT, V. Sociologia crítica do esporte: uma introdução. 2. ed. Ijuí: Ed. Unijuí, 2003. 136p.

BRAGA Jr., M. B.; NETO, F. A. C.; PORTO, M. A.; BARROS, T. A.; LIMA, A. C. M.; SILVA, S. M.; LOPES, M. W. B. Epidemiologic profile and satisfaction level of patients presenting musculoskeletal trauma assisted in a public emergency hospital in Brazil. Acta Ortop Bras 13(3), 2005.

BRAGHIROLLI, E. M.; BISI, G. P.; RIZZON, L. A.; NICOLETTO, U. Psicologia geral. 9. ed. Petrópolis: Vozes, 1997. 
BRINKER, M. R.; O’CONNOR, D. P. The Incidence of Fractures and Dislocations Referred for Orthopaedic Services in a Capitated Population. JBJS., v. 86-A, n. 2, 2004.

BRYANTON, C.; BOSSÉ, J.; BRIEN, M.; McLEAN, J.; McCORMICK A.; SVEISTRUP, H. Feasibility, motivation, and selective motor control: virtual reality compared to conventional home exercise in children with cerebral palsy. Cyberpsychol Behav., Apr; 9(2):123-8, 2006.

BURGAR, C. G.; LUM, P. S.; SHOR, P. C.; MACHIEL, V. L. H. F. Development of robots for rehabilitation therapy: the Palo Alto VA/Stanford experience. J Rehabil Res Dev. Nov-Dec; 37(6):663-73, 2000.

BUTLER, D. P. Wii-habilitation: Is there a role in trauma? Int. J. Care Injured, 41, 883-885, 2010.

CANNON, N. M.; BEAL B. G.; WALTERS K. J. (2001). Diagnosis and Treatment Manual for Physicians and Therapist. 4. ed. Indianapolis: The Hand Center of Indiana, 2001.

CARROUGHER, G. J.; HOFFMAN, H. G.; NAKAMURA, D.; LEZOTTE, D.; SOLTANI, M.; LEAHY, L.; ENGRAV, L. H.; PATTERSON, D. R. The effect of virtual reality on pain and range of motion in adults with burn injuries. J Burn Care Res., Sep-Oct; 30(5):785-91, 2009.

CHEN, C. Y.; NEUFELD, P. S.; FEELY, C. A.; SKINNER, C. S. Factors influencing compliance with home exercise programs among patients with upperextremity impairment. Am J Occup Ther.,Mar-Apr; 53(2):171-80, 1999. 
CHEN, N. C.; JUPITER, J. B. Management of Distal Radial Fractures. J Bone Joint Surg Am., 89:2051-2062, 2007.

COSTA, A. G.; FUCHIWAKI, A. C.; MIRANDA, V. D.; HALPERN, A. The internet as a tool to treat na overweight population. Arq. Bras. Endocrinol. Metab., v.49, n.2, p.303-7, 2005.

COTRAN, R. S.; KUMAR, V.; ROBBINS, S. T. Robbins: Patologia estrutural e funcional. 5. ed. Rio de Janeiro : Guanabara Koogan, 1996. 1251 p.

De MASI, D. (Org.) A sociedade pós-industrial. 3. ed. São Paulo: Editora Senac, 2000. 447 p.

DECKER, J.; LI, H.; LOSOWYJ, D. Wiihabilitation: Rehabilitation of Wrist Flexion and Extension Using a Wiimote-Based Game System. Vivek Prakash Rutgers University, GSET . 2009.

DOVAT, L.; LAMBERCY, O.; GASSERT, W. B.; MAEDER, T.; MILNER, T.; BURDET, E. HandCARE: a cable-actuated rehabilitation system to train hand function after stroke. In: IEEE Transactionon Neural System and Rehabilitation Engineering. 16(6):582-591, 2008.

FERRIGNO, I. S. V. Terapia da Mão: Fundamentos para a prática clínica. São Paulo: Editora Santos, 2007. 157 p.

FRANCISCO, B. R. Terapia Ocupacional. 2. Ed. Campinas, SP: Papirus, 2001. 95 p.

GÁSPARI, J. C.; SCHWARTZ, G. M. The elderly and the emotional resignification of leisure. Psic.: Teor. e Pesq. v.21, n.1, Brasília, Jan./Apr. 2005 
GENTILE, D. A.; ANDERSON, C. A.; YUKAWA, S.; IHORI, N.; SALEEM, M.; MING, L. K.; SHIBUYA, A.; LIAU, A. K.; KHOO, A.; BUSHMAN, B. J.; HUESMANN, L. R.; SAKAMOTO, A. The Effects of Prosocial Video Games on Prosocial Behaviors: International Evidence from Correlational, Longitudinal, and Experimental Studies. Pers Soc Psychol Bull. June; 35(6): 752-763, 2009.

GROTH, G.N. Pyramid of progressive force exercises to the injured flexor tendon. Hand Ther. Jan-Mar; 17(1):31-42, 2004.

GUPTA, A.; O'MALlEY, M. K.; PATAGLU, V.; BURGAR, C. Design, Control and Performance of RiceWrist: A Force Feedback Wrist Exoskeleton for Rehabilitation and Training. Inter Journal of Rob Res, Feb, v. 27, n. 2 233-251, 2008 .

HALPER, D. Robotic brace aids stroke recovery.MIT TechTalk, vol.51, n.22, 2007.

HALTON, J. Virtual rehabilitation with video games: A new frontier for occupational therapy. Occupational Therapy Now, v. 9.6, 2008.

HANDOLL, H.; MADHOK R. Surgical interventions for treating distal radial fractures in adults. Cochrane Database Syst Rev., (3), 2003.

HANSSON, G. A.; BALOGH, I.; OHLSSON, K.; SKERVFVING, S. Measurements of wrist and forearm positions and movements: effect of, and compensation for, goniometer crosstalk. J Electromyogr Kinesiol., Jun; 14(3):355-67, 2004. 
HESSE, S.; SCHMIDT, H.; WERNER, C. Machines to support motor rehabilitation after stroke: 10 years of experience in Berlin. JRRD, 43(5): $671-678,2006$.

HESSE, S.; SCHULTE-TIGGES, G.; KONRAD, M.; BARDELEBEN, A.; WERNWE, C. Robot-Assisted Arm Trainer for the Passive and Active Practice of Bilateral Forearm and Wrist Movements in Hemiparetic Subjects. Arch Phys Med Rehabil, V. 84, June, 2003.

HUIZINGA, J. Homo-ludens: o jogo como elemento da cultura. 2. ed. São Paulo: Perspectiva, 1990. 256p.

HUNTER, J. M.; MARKING, E. J.; CALLAHAN, A. D. Rehabilitation of the hand and upper extremity. 5. ed, Missouri: Ed. Mosby, 2002.

Instituto Brasileiro de Geografia e Estatística - IBGE. Uma Análise das Condições de Vida da População Brasileira, 2009. Disponível em: < http://www.ibge.gov.br/home/estatistica/populacao/condicaodevida/indicadoresmin imos/sinteseindicsociais2009/default.shtm>. Acesso em: Setembro de 2010.

JOHSON, M. J.; LOUREIRO, R. C. V.; HARWIN, W. S. Collaborative telerehabilitation and robot-mediated therapy for Stroke rehabilitation at home or clinic. Intelligent Service Robotics, v. 1(2), 109-121, 2008.

KELLER, T.; PERRY, J. C.; LEIBAR, I. I.; BELDA, J.; SERAPIO, L. S. TeleREHA: Investigation and development of rehabilitation platform for home use and tele-rehabilitation AALIANCE Conference - Malaga, Spain - 11 e 12 Março, 2010.

KREBS, H. I.; HOGAN, N.; AISEN, M. L.; VOLPE, B. T. Robot-aided neurorehabilitation. IEEE Trans Rehabil Eng.;6:75-87, 1998. 
LIPS, P.; JAMESON, K.; BIANCHI, M. L.; GOEMAERE, S.; BOONEN, S.; REEVE, J.; STEPAN, J.; JONELL, O.; SCHOOR, N. M.; DENNISON, E.; KANIS, J. A.; COOPER, C.; Working Group for Quality of Life of the International Osteoporosis Foundation. Validation of the IOF quality of life questionnaire for patients with wrist fracture. Osteoporos Int. 21(1): 61-70, 2010.

LOBÃO, A.S.; EVANGELISTA, B.P.; FARIAS, J.A.L. e GROOTJANS, R. Beginning XNA 3.0 Game Programming: From Novice Computer to Professional. United State of America: Ed. Press, 2009. 422 p.

MA, M.; MCNEILL, M.; CHARLES, D.; MCDONOUGH, S.; CROSBIE, J.; OLIVER, L.; MCGOLDRICK, C. Adaptive Virtual Reality Games for Rehabilitation of Motor Disorders. Lecture Notes in Computer Science, v. 4555, pp. 681-690, 2007.

MADISSON, R.; FOLEY, L.; MHURCHU, C. N.; JULL, A.; JING, Y.; PRAPAVESSIS, H.; RODGERS, A.; HOORN, S. V.; HOHEPA, M.; SCHAAF, D. Feasibility, design and conduct of a pragmatic randomized controlled trial to reduce overweight and obesity in children: The electronic games to aid motivation to exercise (eGAME) study. BMC Public Health., 9: 146, 2009.

MANCINI, M. C.; COELHO, Z. A.C. Raciocínio clínico em Terapia Ocupacional. Em Intervenções da Terapia Ocupacional. Belo Horizonte. Editora UFMG, 2008. MASIA, L.; CASADIO, M.; GIANNONI, P.; SANDINI, G.; MORASSO, P. Performance adaptive training control strategy for recovering wrist movements in stroke patients: a preliminary, feasibility study. Journal of NeuroEngineering and Rehabilitation, 6:44, 2009. 
MASIA, L.; KREBS, H. I.; CAPPA, P.; HOGAN, N. Design and Characterization of Hand Module for Whole-Arm Rehabilitation Following Stroke. IEEE ASME Trans Mechatron., August 1; 12(4): 399-407, 2007.

MASIERO, S.; CELIA, A.; ROSATI, G.; ARMANI, M. Robotic-assisted rehabilitation of the upper limb after acute stroke. Arch Phys Med Rehabil., Feb; 88(2):142-9, 2007.

MAURÍCIO, J.T. Aprender Brincando: O Lúdico na Aprendizagem. Disponível em: 〈http://www.profala.com/arteducesp140.htm>. Acesso em setembro de 2010.

MElo, J. P.; SOUZA, J. C. N.; Dias, N. Do jogo e do lúdico no ensino da educação física escolar. Licere, Belo Horizonte, v.13, n.1, mar, 2010.

MENDES, M. I. B.; MELO, J. P. Notas sobre o corpo, saúde e ludicidade. Licere, Belo Horizonte, v.12, n.4, dez., 2009.

MERIANS, A. S.; JACK, D.; BOIAN, R., TREMAINE, M.; BUERDEA G. C.; ADAMOVICH, S. V.; RECCE, M.; POIZNER, H. Virtual reality-augmented rehabilitation for patients following stroke. Phys Ther, 82(9):898-915, 2002.

MIRANDA, L. M.; FARIAS, S. F. Contributions from the internet for elderly people: a review of the literature. Interface Botucatu, v.13, n.29, Botucatu Apr./June, 2009.

NEF, T.; MIHELJ, M.; RIENNER, R. ARMin: a robot for patient-cooperative arm therapy. Med Biol Eng Comput., Sep;45(9):887-900, Aug 3, 2007.

NÓBREGA, T. P. Corporeidade e educação física: do corpo objeto ao corpo sujeito. 2. ed. Natal: Editora da UFRN, 2009. 
NORTON, K.; OLDS, T. Anthropometrica. Sydney, Austrália, Universidade de New South Wales, 1996.

NUNES, A. P. O. B. et al. Efeitos de um programa de exercício físico nãosupervisionado e acompanhado a distância, via internet, sobre a pressão arterial e composição corporal em indivíduos normotensos e pré-hipertensos. Arq. Bras. Cardiol., v.86, n.4, 2006.

O’NEILL, T. W.; COOPER, C.; FINN, J. D.; LUNT, M.; PURDIE, D. M.; REID, R.; ROWE, A. D.; WOOLF, W. A. Incidence of Distal Forearm Fracture in British Men and Women. Osteoporosis Int. v. 12, n. 7, 555-558, 2001.

OLIVEIRA, L. M.; ARAÚJO, P. M. P. Medida de amplitude articular. In: Manual: Recomendações para avaliação do membro superior. 2. ed. São Paulo: Sociedade Brasileira de Terapeutas da Mão, 2005, pp. 42-54.

PANDYA, S.; FLORENCE, J. M.; KING, W. M.; ROBISON, J. D.; OXMAN, M.; PROVINCE, M. A. Reliability of Goniometric Measurements in Patients with Duchenne Muscular Dystrophy. Physical Therapy, v. 65, N. 9, September, 1985.

QUARENTEI M. S. Do ocupar a criação de territórios existenciais. X Congresso Brasileiro de Terapia Ocupacional. Maio, Goiânia, GO, 2007.

Terapia Ocupacional e Produção de Vida. VII Congresso

Brasileiro de Terapia Ocupacional. Porto Alegre, 2001.

RAHMAN, T. et al. Passive exoskeletons for assisting limb movement. JRRD, V. 43, N. 5, 583-89, 2006. 
RIOS, D. R. Grande dicionário unificado da língua portuguesa. São Paulo: DCL, 2010

SANCHEZ, R. J.; LIU, J.; RAO, S.; SHAH, P.; SMITH, R.; RAHMAN, T., CRAMER, S. C.; BOBROW, J. E.; REINKENSMEYER, D. J. Automating arm movement training following severe stroke: functional exercises with quantitative feedback in a gravity-reduced environment. IEEE Trans Neural Syst Rehabil Eng., Sep;14(3):378-89, 2006.

SARINGER, J.; CULHANE, J. Continuous passive motion device for upper extremity forearm therapy. United State Patent 5,951,499. Sep.1999.

SIMÕES Jr., J. G. O pensamento vivo de Marx. Martin Claret Editores, 1985. 112 p.

SINGER, B. R.; McLAUCHLAN, G. J.; ROBINSON, C. M.; CHRISTIE, J. Epidemiology of fractures in 15000 adults. The Influence of Age and Gender. The journal of Bone and Joint Sur, v. 80-B, n. 2, Março, 1998.

STEIN, J.; NARENDRAN, K.; McBEAN, J.; KREBS, K.; HUGHES, R. Electromyography-controlled exoskeletal upper-limb-powered orthosis for exercise training after stroke. Am J Phys Med Rehabil., Apr; 86(4):255-61, 2007.

SOARES, S. R.; CARVALHO, H. A. Implementação de indicadores de qualidade e desempenho através do gerenciamento por projeto. Estudo de caso dos locais de produção de uma empresa em Curitiba. Disponível em $<$ http://www.fae.edu/publicacoes/pdf/IIseminario/sistemas/sistemas_09.pdf $>$. Acesso em maio de 2010. 
SUZUKI, F. T. I.; MATIAS, M. V.; SILVA, M. T. A. S.; OLIVEIRA, M. P. M. T. The use of video, computer, and internet games by a sample of college students from the University of São Paulo. J. bras. Psiquiatr. V.58. n.3. Rio de Janeiro, 2009.

SVEISTRUP, H.; McCOMAS, J.; THORNTON, M. et al. Experimental studies of virtual reality-delivered compared to conventional exercise programs for rehabilitation. Cyberpsychol Behav, Jun; 6(3):245-9, 2003.

TANG, J.; RYU, J.; OMOKAWA, S.; HAN, J.; KISH, V. Biomechanical evaluation of wrist motor tendon after fractures o the distal radius. The Journal of Hand Surgery, 24, 121-132, 1999.

TIMMERMANS, A. A. A.; SEELEN, H. A. M.; WILLMANN, R. D.; KINGMA, H. Technology-assisted training of arm-hand skills in stroke: concepts on reacquisition of motor control and therapist guidelines for rehabilitation technology design. $\mathbf{J}$ Neuroeng Rehabil., 6: 1, 2009.

VANAKEN, L.; NOTELAERS, S.; RAYMAEKERS, C.; CONINX, K.; HOOGEN, W.; IJSSELSTEIJN, W.; FEYS, P. Game-based Collaborative Training for Arm Rehabilitation of MS Patients: A Proof-of-concept Game. Belgium. Paper presented at: GameDays, Darmstadt, Germany, March 25-26, pp. 65-75, 2010. WILLIAMS, D. J.; KREBS, H. I.; HOGAN, N. A robot for wrist rehabilitation. Engineering in Medicine and Biology Society. Proceedings of the 23rd Annual International Conference of the IEEE, 2001.

WOODWORTH, R. S. Psicologia. São Paulo: Cia. Editora Nacional, 1973. 


\begin{abstract}
ANEXOS
Segue anexados o Termo de Consentimento Livre Esclarecido assinado por todos os participantes da pesquisa, o questionário de avaliação do sistema utilizado, e a Tabela $5.1 \mathrm{com}$ as respostas do questionário.
\end{abstract}




\section{ANEXO A \\ Termo de Consentimento Livre Esclarecido}

1. Você está sendo convidado para participar da pesquisa "Elaboração de um aparelho reabilitador e avaliador da amplitude de movimento e força pós fratura da extremidade distal do rádio".

2. O projeto justifica-se pelo fato de as informações coletadas serem importantes para a construção de um aparelho para auxiliar na reabilitação de fratura da extremidade distal do rádio.
a. Você foi selecionado de forma aleatória e sua participação não é obrigatória.
b. Os objetivos deste estudo é identificar aspectos relevantes para a utilização de um aparelho em elaboração.
c. Sua participação nesta pesquisa consistirá em utilizar o aparelho e responder a um questionário.

3. Não haverá benefícios diretos em curto prazo de sua participação, como também não haverá despesas ou compensação financeira em qualquer fase do estudo.

a. Em um aparelho como este, onde há o contato direto com o ser humano, há risco de lesão de punho se os movimentos realizados pelo aparelho forem maiores que a amplitude de movimento biomecânico da articulação. A velocidade e a força aplicadas pelo aparelho no movimento passivo do punho podem ser excessivas, lesionando a região. Para que isto não ocorra, foi adotado sistemas de segurança em paralelo, com atuação elétrica e/ou mecânica e restrição da potência do motor. Desta maneira, há o controle do movimento, força e velocidade, previnindo lesões. Testes serão realizados previamente.

4. Considerando os objetivos estabelecidos, mecanismos de proteção contra acidentes e aplicação de questionários, a pesquisa possui riscos mínimos tanto nos aspectos físicos, psíquicos e morais do participante. Dessa forma, em caso de cansaço ou indisposição o teste e o questionário serão imediatamente suspensos e, havendo concordância, serão remarcados para outro momento oportuno, para que você não tenha qualquer prejuízo.

5. Você terá acesso, a qualquer momento, às informações atualizadas sobre procedimentos, riscos e benefícios relacionados à pesquisa, e garantia de receber respostas a qualquer pergunta ou esclarecimento sobre a pesquisa. As informações sobre o acompanhamento da pesquisa e para contato quando necessário, podem ser feitas diretamente com: Gisele Gonsalez Ito Cel: 1681422143 ou 87 99434970, email: gito29@hotmail.com.

6. Você terá a garantia de esclarecimentos, antes e durante o curso da pesquisa, a respeito dos procedimentos.

7. A qualquer momento você pode desistir de participar e retirar seu consentimento. Você pode se recusar a responder qualquer questão do questionário ou parar de testar o aparelho sem que isso cause qualquer tipo de prejuízo em sua relação com a pesquisadora ou com a instituição envolvida. Sua recusa em participar da pesquisa 
também não trará nenhum prejuízo em sua relação com a pesquisadora ou com a instituição.

8. As informações obtidas através dessa pesquisa serão confidenciais e asseguramos o sigilo sobre sua participação. Os dados não serão divulgados de forma a possibilitar sua identificação. O instrumento de coleta de dados não contém campo para colocar o nome do participante para que sua identidade seja mantida no anonimato e assegurada sua privacidade.

9. A pesquisa não acarreta em despesas decorrentes da participação.

10. Você receberá uma cópia deste termo onde consta o telefone e o endereço do pesquisador principal, podendo tirar suas dúvidas sobre o projeto e sua participação, agora ou a qualquer momento.

Gisele Gonsalez Ito

Cel:16-81422143 ou 87-99434970, gito29@ hotmail.com

R. Lamartine Babo, 71 Pedra do Bode, Petrolina, PE

CEP:56332-530

Declaro que entendi os objetivos, riscos e benefícios de minha participação na pesquisa e concordo em participar.

O pesquisador me informou que o projeto foi aprovado pelo Comitê de Ética em Pesquisa em Seres Humanos da UFSCar que funciona na Pró-Reitoria de Pesquisa da Universidade Federal de São Carlos, localizada na Rodovia Washington Luiz, Km. 235 - Caixa Postal 676 - CEP 13.565-905 - São Carlos SP - Brasil. Fone (16) 3351-8110. Endereço eletrônico: cephumanos@power.ufscar.br

São Carlos, de de 2010 


\section{ANEXO B \\ Questionário de Avaliação}

Este Questionário será utilizado para a coleta de dados da dissertação de mestrado de Engenharia Mecânica, da Escola de Engenharia de São Carlos (EESC) da Universidade de São Paulo (USP), realizado pela terapeuta ocupacional Gisele Gonsalez Ito, sobre a orientação do Prof. Dr. Glauco Augusto de Paula Caurin e com a colaboração do doutorando MSC. Ricardo Cezar Joaquim e Prof. Dr. Adriano Almeida Gonçalves Siqueira.

Consiste, após explicação e teste do aparelho, na escolha de 1 alternativa para cada pergunta com espaço opcional para discorrer sobre o assunto e uma resposta discursiva no final.

1. A qual categoria de usuários você pertence?
a) ( ) Profissional da área de Saúde.
b) ( ) Profissional da área de Exatas.
c) ( ) Adulto que não pertence às categorias a) e b).
d) ( ) Terceira idade que não pertence às categorias a) e b).

2. Utiliza ou utilizou algum serviço de reabilitação física?
a) ( ) mais de 11 atendimentos.
b) ( ) de 2 a 10 atendimentos.
c) ( ) 1 atendimento.
d) ( ) nunca.

3. Com relação à ergonomia (ajustes do aparelho para adaptar-se aos diferentes tamanhos), você está:
a) ( ) Muito satisfeito
b) ( ) Satisfeito 

c) ( ) Pouco satisfeito
d) ( ) Insatisfeito

Críticas, sugestões:

4. Com relação ao conforto, você está:
a) ( ) Muito satisfeito
b) ( ) Satisfeito
c) ( ) Pouco satisfeito
d) ( ) Insatisfeito

Críticas, sugestões:

5. Com relação ao design do aparelho, você está:
a) ( ) Muito satisfeito.
b) ( ) Satisfeito.
c) ( ) Pouco satisfeito.
d) ( ) Insatisfeito.

Críticas, sugestões:

6. Com relação ao sentimento de segurança para utilizar o aparelho, você está:
a) ( ) Muito satisfeito.
b) ( ) Satisfeito.
c) ( ) Pouco satisfeito.
d) ( ) Insatisfeito.

Críticas, sugestões:

7. Com relação à facilidade de limpeza do aparelho, você está: 

a) ( ) Muito satisfeito.
b) ( ) Satisfeito.
c) ( ) Pouco satisfeito.
d) ( ) Insatisfeito.

Críticas, sugestões:

8. Com relação à facilidade de compreensão e utilização dos recursos do aparelho, você está:
a) ( ) Muito satisfeito.
b) ( ) Satisfeito.
c) ( ) Pouco satisfeito.
d) ( ) Insatisfeito.

Críticas, sugestões:

9. Com relação à confiabilidade (habilidade do aparelho em fazer o serviço prometido com confiança e precisão), você está:
a) ( ) Muito satisfeito.
b) ( ) Satisfeito.
c) ( ) Pouco satisfeito.
d) ( ) Insatisfeito.

Críticas, sugestões:

10. Com relação à utilidade do aparelho, você está:
a) ( ) Muito satisfeito.
b) ( ) Satisfeito.
c) ( ) Pouco satisfeito. 
d) ( ) Insatisfeito.

Críticas, sugestões:

11. Com relação à facilidade de transporte do aparelho, você está:
a) ( ) Muito satisfeito.
b) ( ) Satisfeito.
c) ( ) Pouco satisfeito.
d) ( ) Insatisfeito.

Críticas, sugestões:

12. Com relação ao jogo motivar a reabilitação, você está:
a) ( ) Muito satisfeito.
b) ( ) Satisfeito.
c) ( ) Pouco satisfeito.
d) ( ) Insatisfeito.

Críticas, sugestões:

13. Com que frequiência você utilizaria o aparelho caso tivesse que reabilitar os movimentos do punho e fosse recomendado a utilização do aparelho a cada 2 horas?
a) ( ) Com muita frequência (todos os dias, a cada 2 horas).
b) ( ) Frequentemente (mais de uma vez por dia)
c) ( ) Com pouca frequência (uma vez por dia ou menos).
d) ( ) Nunca.

14. Outras críticas ou sugestões para a melhoria do aparelho? 